\title{
First comprehensive morphological analysis on the metapodials of Giraffidae
}

\author{
María Ríos, Melinda Danowitz, and Nikos Solounias
}

\begin{abstract}
Giraffids are a group of relict pecoran ruminants with only two living taxa. During the Miocene, however, this group was much more diverse, with more than 20 different species showing a wide range of variability. In addition to many other parts of the skeleton this variability is also represented in their metapodials. We find inter-specific anatomical differences in the giraffid metapodials; each taxon evaluated possesses a unique combination of limb morphologies. The proximo-palmar/plantar metapodial surface provides useful characteristics and allows for genus identifications and comparisons. We describe the central trough of the metapodial shaft; when combined with the absolute length of the limb, the depth of this trough allows for better separation between taxa. We find that the metacarpal robustness index exceeds that of the metatarsals in all except one giraffid evaluated, supporting a front-loaded body weight distribution, consistent with the elongated cervicals or large ossicones seen in many taxa. The morphological features of the giraffid metapodials, as well as the limb lengths and proportions can be a useful tool for phylogenetic analysis.
\end{abstract}

Maria Rios. Departamento de Paleobiología, Museo Nacional de Ciencias Naturales-Consejo Superior de Investigaciones Científicas, 2 Gutiérrez Abascal, Madrid, 28006, Spain. maria.rios.iba@mncn.csic.es Melinda Danowitz. Department of Anatomy, New York Institute of Technology College of Osteopathic Medicine, 8000 Northern Boulevard, Old Westbury, NY 11568, USA. mdanowit@nyit.edu Nikos Solounias. Department of Anatomy, New York Institute of Technology College of Osteopathic Medicine, 8000 Northern Boulevard, Old Westbury, NY 11568, USA. And Department of Paleontology, American Museum of Natural History, Central Park West at $79^{\text {th }}$ Street, New York, NY 10024, USA. nsolouni@nyit.edu

Keywords: Giraffidae; metapodial; morphology; limbs; Ruminantia; anatomy

Submission: 3 March 3026 Acceptance: 16 November 2016

Ríos, María, Danowitz, Melinda, and Solounias, Nikos. 2016. First comprehensive morphological analysis on the metapodials of Giraffidae. Palaeontologia Electronica 19.3.50A: 1-39

palaeo-electronica.org/content/2016/1702-the-metapodials-of-giraffidae

Copyright: @ December 2016 Society of Vertebrate Paleontology. This is an open access article distributed under the terms of the Creative Commons Attribution License, which permits unrestricted use, distribution, and reproduction in any medium, provided the original author and source are credited. creativecommons.org/licenses/by/4.0/ 


\section{INTRODUCTION}

Giraffids are a relict group of pecoran ruminants characterized by the possession of twolobed canines and a particular kind of cranial appendage called ossicones (Hamilton, 1978). Though currently there are only two living species, the okapi, Okapia johnstoni and the giraffe, Giraffa camelopardalis, in the past it was a much more diverse group (Dagg and Foster, 1976; Geraads, 1986). Appearing by the beginning of the middle Miocene, the giraffids reached their maximum diversity during the late Miocene (Bohlin, 1926; Hamilton, 1978; Kostopoulos, 2009). They were represented by more than 20 different species, which were present throughout the Old World, from China in the East to the Iberian Peninsula in the West (Borisiak, 1914; Alexjew, 1916; Bohlin, 1926; Schlosser, 1921; Crusafont, 1952; Kostopoulos, 2009). During that time, several giraffids species were found together in the same site, such as on Samos (Greece) (Solounias, 2007), showing that different representatives of the family were coexisting during that period of time (Danowitz et al., 2016). This diversity was also reflected in the variability of the skeleton of the different giraffid species (Colbert, 1935; Hamilton, 1978; Solounias, 2007). In addition to the variation of the scarce skull or vertebral remains, variability can be found in much more abundant postcranial limb elements, as shown by the morphology of the giraffid metapodials (Bohlin, 1926). The metacarpals and the metatarsals of giraffids vary substantially in absolute size, proportions, and morphology.

Metapodial structure is useful for the interpretation of locomotion, limb stability, and phylogenetic relationships at the familial level. Past research demonstrated that a negative allometric relationship exists between metapodial length and body size (Leinders and Sondaar, 1974; Scott, 1985), and that body size variation can lead to asymmetries at the distal end of metapodials (Bartosiewicz et al., 1993). Allometric limb studies have also shown that the distal limbs of ungulates, such as the metacarpals and metatarsals, are more diversified than the proximal portions of the limbs (McMahon, 1975). The shortening of metapodials, as well as the fusion of the individual digits to form a single cannon bone, can increase the stability of the limb, at the expense of speed (Leinders and Sondaar, 1974; van der Geer, 2005). Previously established morphological features used for ungulate limb comparisons include degree of fusion of the third and fourth metapodials, splaying of the distal end of the metapodials, and the degree of reduction of the keels of the distal condyles (Janis et al., 2002).

Studies on metapodial proportions have demonstrated that limb bones can be used to identify specimens at the genus or even species level (Breyer, 1983). Solounias (2007) demonstrated that giraffids can be separated by metapodial characteristics, and mentioned key morphological features that identify individual species, such as the depth of the central trough, and the length of the shaft. The present study expands on these and includes additional anatomical features that define different giraffids. We provide morphological features that can be used to characterize giraffids at the genus level.

Morphological studies often focus on the distal aspect of metapodials (e.g., Leinders, 1979; Janis and Scott, 1987). We incorporate the anatomical features of the entire metapodial and provide detailed descriptions of the proximo-palmar/plantar metapodial surface, which exhibits distinct characteristics distinguishable between species. In the present study, we provide an in-depth analysis of morphological and dimensional features to classify the genera of Giraffidae and to create a solid base for the inclusion of the metapodial characteristics in future phylogenetic analyses.

\section{MATERIAL AND METHODS}

\section{Material}

Institutional abbreviations. AMNH: American Museum of Natural History (New York, USA)

IPS: Institut Català de Paleontologia (Sabadell, Spain)

KNM: Kenya National Museums (Nairobi, Kenya)

MGL: Geological Museum of Lausanne (Lausanne, Switzerland)

MGUV: Museo de Geología de la Universidad de Valencia (Burjasot, Spain)

MNCN: Museo Nacional de Ciencias Naturales (Madrid, Spain)

MNHN: Muséum national d'Histoire Naturelle (Paris, France)

NHM: Natural History Museum (London, UK)

NHMBe: Natural History Museum of Bern (Bern, Switzerland)

We analyze the metapodials of Birgerbohlinia schaubi, Bohlinia attica, Bramatherium megacephalum, Canthumeryx sirtensis, Decennatherium pachecoi, Giraffa camelopardalis, Helladotherium duvernoyi, Okapia johnstoni, Palaeotragus rouenii, Samotherium major, and Sivatherium giganteum. 


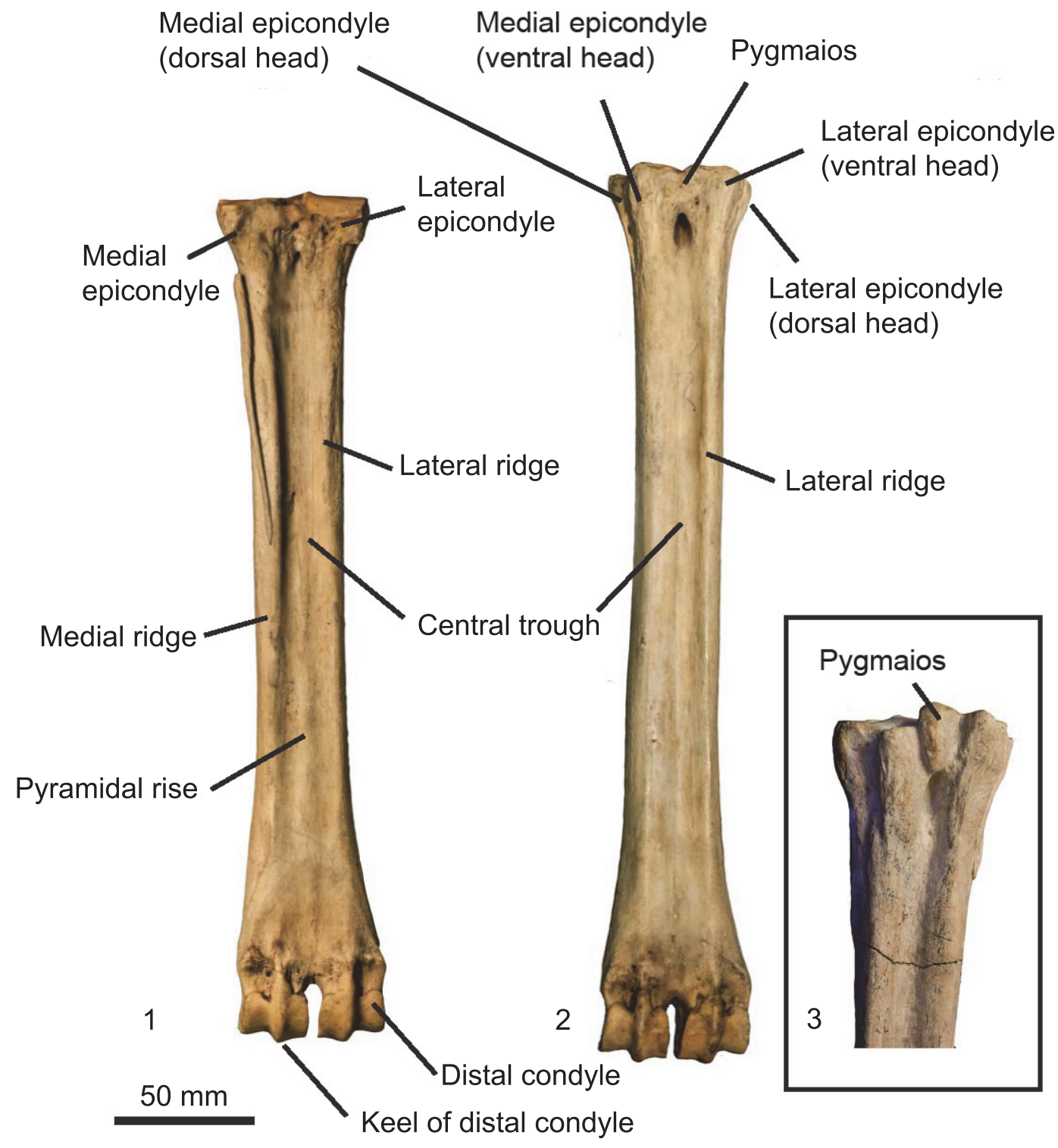

FIGURE 1. Drawing indicating the different features described. Terminology using the right metapodials of Okapia johnstoni. AMNH 51218: 1, metacarpal palmar view; 2, metatarsal plantar view; and Samotherium major from Samos, MGL S 382; 3, pygmaios. Scale bar equals $50 \mathrm{~mm}$.

\section{Methods}

We establish terminology to describe anatomical features on ruminant metapodials (Figure 1). Descriptions of these characteristics are listed below. Using this terminology, we describe morphological features and compare measurements of metacarpals and metatarsals of selective extant and extinct giraffid species. Terminology also follows the Nomina Anatomica Veterinaria (2012).
Our descriptions focus on the palmar and plantar metapodial surface.

General metapodial features. There are several distinct characteristics (Figure 1):

Medial epicondyle-medial, palmar/plantar bony protrusion on the proximal-most region of the shaft, which corresponds to the third articular facet. This comprises the medial aspect of the basis.

Lateral epicondyle-lateral, palmar/plantar bony protrusion on the proximal-most region 


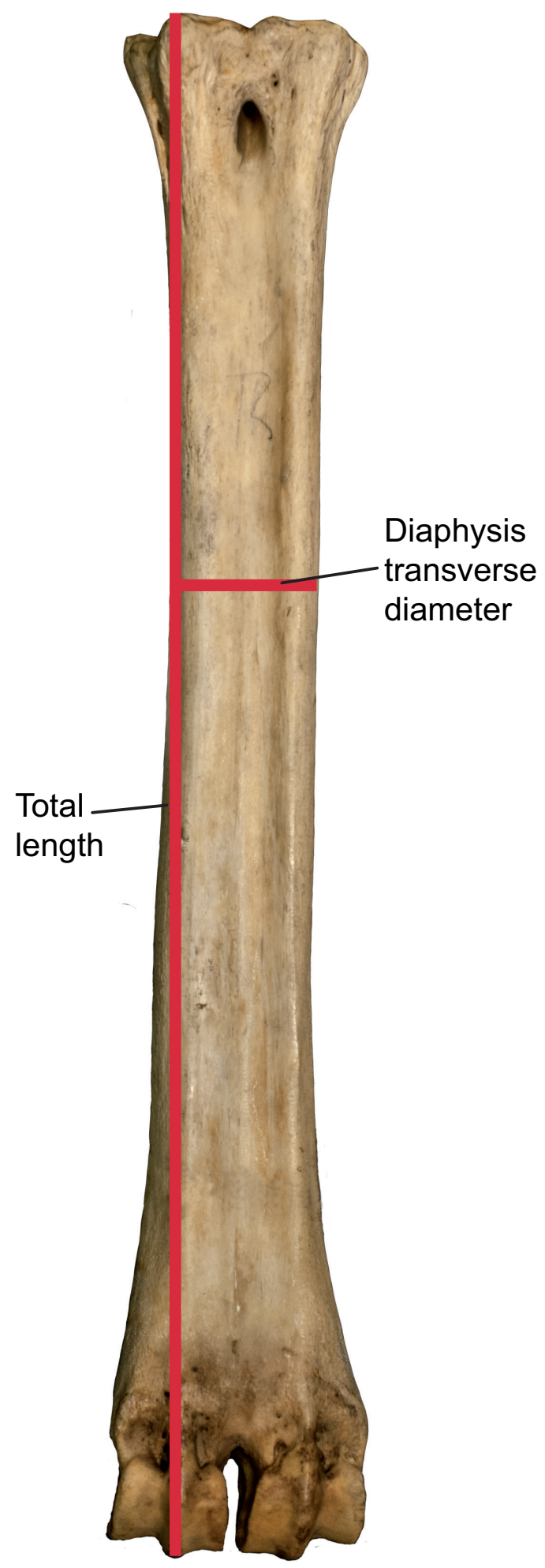

FIGURE 2. Measurements applied to the giraffid metapodials, based on those proposed by Quiralte (2011), using the same specimen as in figure 1 . of the shaft, which corresponds to the fourth articular facet. This comprises the lateral aspect of the basis.

Medial ridge-elongated elevation of bone on the medial, palmar/plantar metapodial surface.

Lateral ridge-elongated elevation of bone on the lateral, palmar/plantar metapodial surface. The medial and lateral ridges together create a central trough that varies in depth and length; this depth is congruent with the size of the ridges.

Pyramidal rise-bony elevation on the palmar/ plantar metapodial surface within the central trough. The length of the pyramidal rise is variable and can extend the length of the metapodial or be confined to the distal shaft. This elevation likely corresponds to an internal septum where the central cavity of the bone is divided into two areas, which can be seen in cross sectional view of young giraffes.

Metacarpal features. The articular surface is largely composed of two articular facets, which are the facets of the third and fourth metacarpals.

Third articular facet-is the largest and articulates with the trapezoideocapitatum.

Fourth facet-is smaller and articulates with the os hamatum. Often lower than the third facet and is separated by a step.

Synovial fossa-small fossa of variable size and shape that can be open or closed on the palmar surface. The fossa is positioned between the third and fourth articular facets.

Metatarsal features. There are several distinct facets at the articular surface of the metatarsals. The lateral facet articulates with the os naviculocuboideum; there is often a distinct lateral constriction. The larger medial facet articulates with the os cuneiforme intermediolaterale; it is located dorsally and may contact the os cuneiforme mediale facet. The smaller medial facet articulates with the os cuneiforme mediale.

Pygmaios-bony protrusion at the plantar-proximal surface of the metatarsal between the medial and lateral articular facets. It is often adjacent to the median plane.

The medial and lateral epicondyles of the metatarsals are often split into two heads. The plantar head is often continuous with the medial/ lateral ridge, and the dorsal head is often continuous with the main shaft. 


\section{Measurements}

All measurements were taken with Mitutoyo ABSOLUTE 500-196-20 digital calipers (Inch/Metric, 0-150 mm. Range, +/-0.02 mm. Accuracy, 0.01 $\mathrm{mm}$. Resolution). We follow the set of measurements proposed by (Quiralte, 2011) (Figure 2). The data was plotted and analyzed using SPSS software to obtain dispersion and box-and-whiskers plots representing the different aspects of the variability of giraffid metapodials, including length and the midshaft transverse diameter.

Using these measurements, we also calculate the robustness index (RI), which is calculated using the following formula:

$\mathrm{RI}=$ Midshaft minimum transverse diameter/ Length * 100

This index is commonly used in studies concerning allometry and biomechanics to represent the robustness of the bone (Hamilton, 1978; Bover et al., 2010; Fragomeni and Prothero, 2011; Woodman and Gaffney, 2014).

\section{RESULTS}

\section{Description of the metacarpals of Giraffidae}

Class MAMMALIA Linnaeus, 1758

Order CETARTIODACTYLA Montgelard, Catzeflis and Douzery, 1997

Suborder RUMINANTIA Scopoli, 1777

Family GIRAFFIDAE Gray, 1821

Genus HELLADOTHERIUM Gaudry, 1861

Type species. Camelopardalis duvernoyi (Gaudry and Lartet, 1856)

Helladotherium duvernoyi Gaudry, 1861

Specimens. MNHN PIK 1658, MNHN PIK1527

Description. The medial and lateral epicondyles are sub-equal in size, where the medial epicondyle is slightly larger (Figure 3). The lateral epicondyle is confined. There is a triangular flattened area on the lateral epicondyle, distal to the articular surface. There is an obliquely oriented groove on the lateral epicondyle separating it into two heads (Figure 4). The medial epicondyle is fuller, circle-sector shaped, and extends onto the medial ridge. There is a slight depression on the medial epicondyle, distal to the articular surface. The lateral epicondyle is triangular in shape. There is an obliquely oriented groove on the surface of the medial epicondyle. Both epicondyles are notably flat. There is a deep groove that separates the medial and lateral epicondyles, and continues onto the central trough. The medial ridge has a sharp surface, whereas the lateral ridge has a dish-shaped sur- face, where the central portion is flattened and concave (Figure 5.1). The central trough is deep and flattens distally (Figures 6.1,7). Proximally, the lateral and medial ridges appear approximated towards the midline, which creates an hourglass shape. The medial ridge exhibits an elongated flattened surface on the medial edge. Both ridges completely flatten at the distal third of the shaft. The distal shaft is notably flat. The keels of the distal condyles are confined and do not extend onto the distal palmar shaft.

Genus BRAMATHERIUM Falconer, 1845

Type species. Bramatherium perimense Falconer, 1845

Bramatherium megacephalum Lydekker, 1876

Specimens. AMNH 29820, AMNH 9820

Description. There is a pronounced step between the medial and lateral facet at the articular surface. The synovial fossa is open, oval, and large. The medial and lateral epicondyles are asymmetrical in size and morphology, and strongly flare outward on the medial and lateral edges (Figure 8). The medial and lateral epicondyles are separated centrally by a wide, deep groove. The articular surface extends onto the palmar surface of the lateral epicondyle. There is a longitudinal groove on the lateral surface of the lateral epicondyle, which continues down the lateral aspect of the lateral ridge (Figure 4). The medial epicondyle is circle-sector shaped and larger, and the lateral epicondyle is smaller and triangular. There is a wide, deep fossa at the proximal edge of the medial epicondyle. There is an extra, elongated bony protrusion on the medial edge of the proximal shaft (Figure 5.2). The medial ridge is rounded and extends from the medial epicondyle to the distal condyle. It is very prominent and full. The lateral ridge is sharper, and also extends from the lateral epicondyle to the distal condyle. The central trough is deep and continuous throughout the length of the metacarpal, but it becomes progressively flatter towards the distal edge. The keels of the distal condyles extend onto the palmar distal shaft.

Genus SIVATHERIUM Falconer and Cautley, 1836

Type species. Sivatherium giganteum Falconer and Cautley, 1836

Sivatherium giganteum Falconer and Cautley, 1836

Specimen. NHM UK 39533

Description. The medial and lateral epicondyles are asymmetrical in size and morphology (Figure 9). The medial part is smaller, triangular, and exhib- 

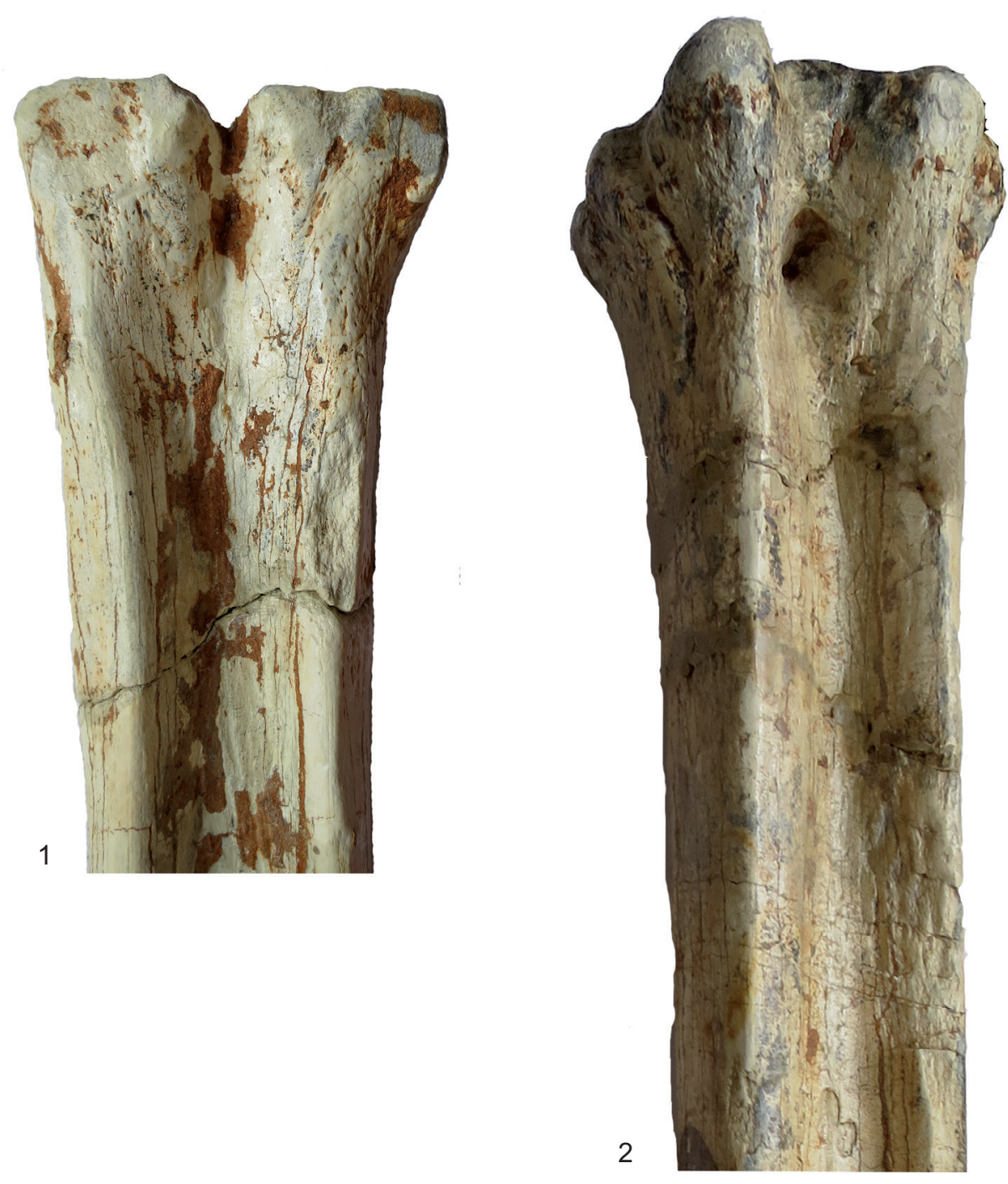

FIGURE 3. Helladotherium duvernoyi from Pikermi. 1, left metacarpal (reversed) MNHN 1658; 2, right metatarsal MNHN 1564.

its several raised ridges on the surface. The lateral epicondyle is larger, square shaped, and possesses several sub facets (Figure 7). There is a very faint, obliquely oriented groove on the lateral epicondyle (Figure 5.3). The proximal articular surface extends slightly onto the palmar surface of the lateral epicondyle. There is a deep groove separating the medial and lateral epicondyles which strongly flare outward, and it continues onto the central trough. The medial ridge is rounded and extends from the distal aspect of the medial epicondyle. The ridge is thicker at the midshaft, is thin proximally and distally, and it ends abruptly towards the distal shaft. The lateral ridge is sharper and is continuous longitudinally on the shaft. There is an elongated oval fossa lateral to the lateral ridge, which extends from the lateral epicondyle to midshaft (Figure 4). The central trough is intermediate in depth, and it flattens towards the distal shaft. The distal metacarpal is spatula shaped and flares outward. The lateral distal condyle extends further distally than the medial distal condyle (distance $\sim 4 \mathrm{~mm}$ ). The lateral aspect of the lateral distal condyle flares whereas the medial aspect of the medial distal condyle is more vertical. The keels of the distal condyles extend onto the palmar distal shaft.

Genus DECENNATHERIUM Crusafont, 1952

Type species. Giraffinae? pachecoi (Crusafont, 1952)

Decennatherium pachecoi Crusafont, 1952 
Selected Metacarpal Features A

Fossa on the medial epicondyle: absent

small

large

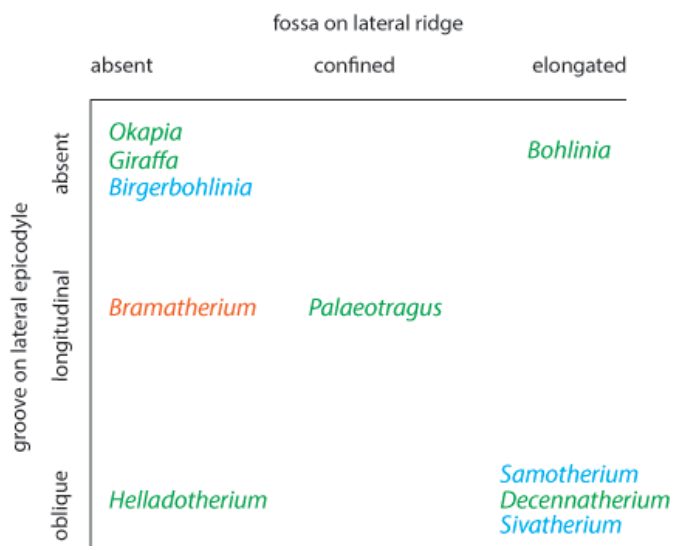

FIGURE 4. Three selected metacarpal characteristics. This simplified table can be used to facilitate specimen identifications and differentiate between different giraffid taxa.

\section{Specimen. MNCN 42769}

Description. The medial and lateral epicondyles are asymmetrical in size and morphology. The medial epicondyle is circle-sector shaped and flatter. The lateral epicondyle is triangular shaped and fuller, and the distal aspect continues onto the lateral ridge (Figure 5.4). There is a small circular knob close to the median plane. An obliquely oriented groove separates the lateral epicondyle into a laterally flaring head that connects distally to the lateral ridge (Figure 4). The proximal articular surface extends slightly onto the palmar surface of the lateral epicondyle. There is a shallow groove on the medial aspect of the medial epicondyle, which ends distally in the central trough. A deep, narrow groove separates the medial and lateral epicondyles and continues onto the central trough. The medial ridge is sharper, and it flattens towards the distal shaft, whereas the lateral ridge is rounder and it also flattens towards the distal shaft. There is an elongated oval fossa on the lateral aspect of the lateral ridge. The central trough is intermediatedeep in depth proximally (Figure 7), and becomes progressively shallower and is flat distally. The lateral aspect of lateral distal condyle flares, whereas the medial aspect of the medial distal condyle is more vertical. The keels of the distal condyle continue slightly onto the palmar shaft.

Genus BIRGERBOHLINIA Crusafont, 1952
Type species. Birgerbohlinia schaubi Crusafont, 1952

Birgerbohlinia schaubi Crusafont, 1952

Specimens. IPS 935, IPS 7640, IPS 5059, IPS 5060, IPS 5014, IPS 7629, IPS 5010, IPS 5061, MGUV 7806, AMNH 20610

Description. The synovial fossa is open and is oval in shape (Figure 10). The step between the two facets is thin and well-marked. The medial and lateral epicondyles are asymmetrical. The medial epicondyle is more prominent and square. The lateral epicondyle is triangular in shape, is less developed, and has a fossa close to the articular surface (proximodorsal) (Figure 5.5). The lateral epicondyle continues onto the palmar lateral ridge. There is a well-developed proximal dorsal tuberosity. The medial ridge is rounded and the lateral ridge is sharp. They create a deep central trough that flattens two-thirds down the shaft (Figure 6.2). Both the medial and lateral ridges are rounded proximally and become progressively flatter distally. The distal shaft flares more on the medial edge. The keel of the distal condyles slightly extends onto the palmar distal shaft. The articular edge is vertical.

Genus OKAPIA Lankester, 1901

Type species. Equus johnstoni (Sclater, 1901)

Okapia johnstoni Lankester, 1901

Specimens. AMNH 51196, AMNH 51107, AMNH 51218

Description. The medial and lateral epicondyles are symmetrical in size (Figure 7). The proximal articular surface extends onto the palmar lateral epicondyle. There is a rounded circular protrusion on the medial aspect of the proximal medial epicondyle and a slight protrusion of the lateral aspect of the lateral epicondyle. There is also a flattened, fainter second circular protrusion on the central aspect of the medial epicondyle. There is a slight depression on the palmar surface of the medial epicondyle. The medial epicondyle is squared shaped and the lateral is triangular (Figure 5.6). There is shallow groove that separates the medial and lateral epicondyles. There is an elongated, rod-like bony protrusion on the medial aspect of the shaft that extends slightly distal to the medial epicondyle to midway down the shaft. It is fused to the medial shaft distally, and is sometimes fused proximally and throughout the length. The central trough is intermediate in depth, and it flattens distally (Figure 6.3). There is a distinct pyramidal rise. The medial and lateral ridges are rounded and full. The medial edge of the shaft flares towards the distal 


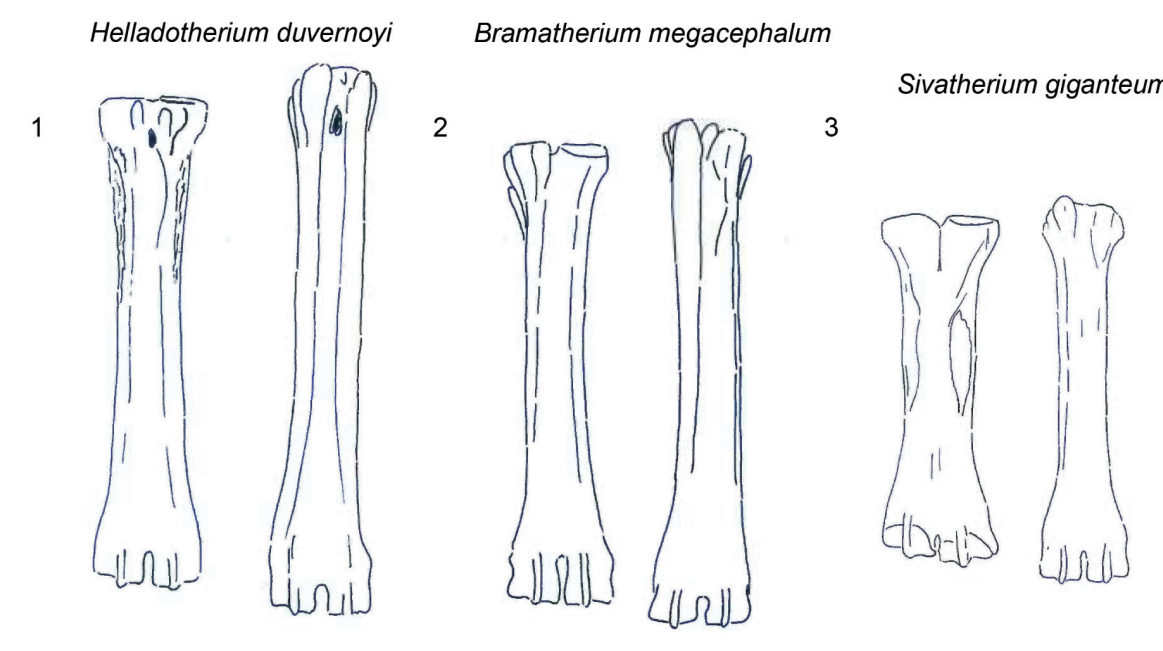

Decennatherium pachecoi

Birgerbohlinia schaubi
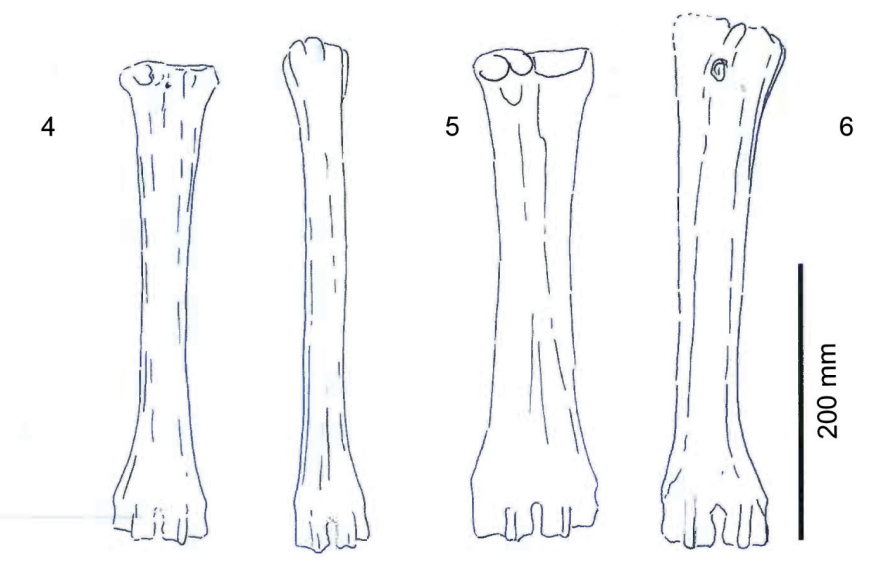

Okapia johnstoni

6

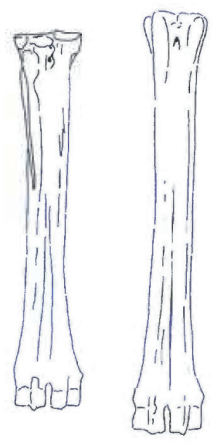

FIGURE 5. Palmar views of the right metacarpals (left) and plantar views of metatarsals (right) of certain Giraffidae. 1, Helladotherium duvernoyi, late Miocene, Pikermi, NHM 11382 (metacarpal), MNHNP 1554 (metatarsal) (both reversed); 2, Bramatherium megacephalum, late Miocene-Pliocene, Siwaliks, AMNH 29820, (metacarpal), AMNH 19668 (metatarsal) ; 3, Sivatherium giganteum, Pleistocene, Siwaliks, NHM 39553 (metacarpal), NHM 39752 (metatarsal); 4, Decennatherium pachecoi, late Miocene, Los Valles de la Fuentidueña, MNCN 42769 (metacarpal), MNCN 42764 (metatarsal) (both reversed); 5, Birgerbohlinia schaubi, late Miocene, Piera, IPS 5060 (metacarpal), Crusafont, 1952, fig. 15-5 (metatarsal), (both reversed); 6, Okapia johnstoni, Zaire, AMNH 51196 (metacarpal), AMNH 51196 (metatarsal). Scale bar equals $200 \mathrm{~mm}$.

condyle. The keels of the distal condyle extend onto the palmar distal shaft. The distal condyle is distinctly separated from the distal shaft.

Genus SAMOTHERIUM Forsyth Major, 1888

Type species. Samotherium boissieri Forsyth Major, 1888

Samotherium major Bohlin, 1926

Specimens. AMNH 20595, NHMBe 711, AMNH 22970
Description. The medial and lateral epicondyles are similar in size and asymmetrical in morphology (Figure 11). The lateral epicondyle is triangular shaped and fuller, and the distal aspect continues onto the lateral ridge. The proximal articular surface extends slightly onto the palmar surface of the lateral epicondyle. There is a small circular knob close to the median plane. An obliquely oriented groove separates the lateral epicondyle into a laterally flaring head that connects distally to the lat- 

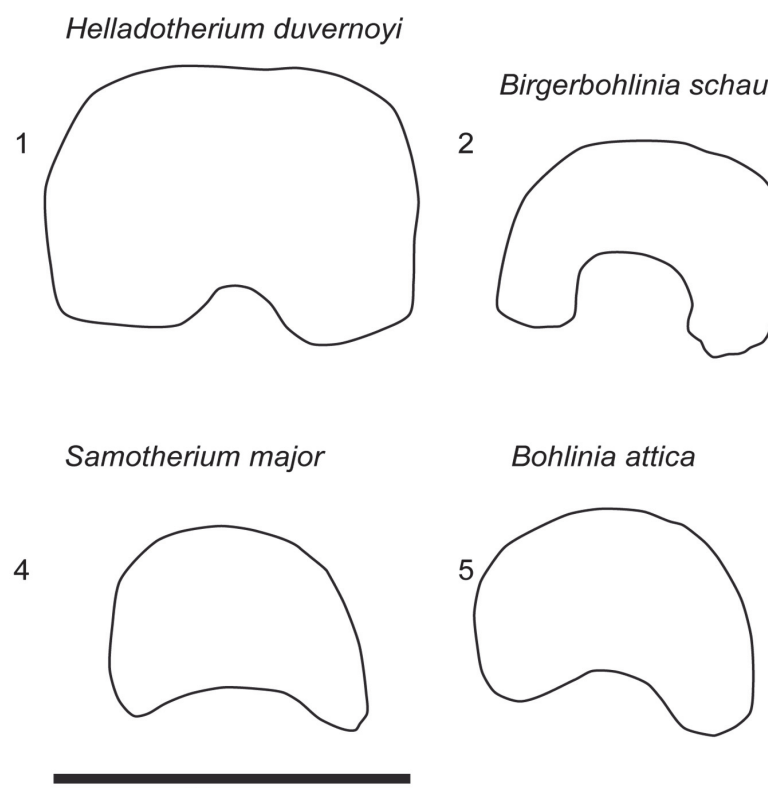

$80 \mathrm{~mm}$
Bohlinia attica

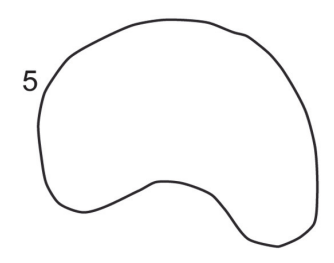

Okapia johnstoni

3

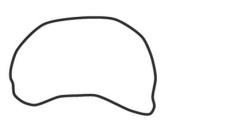

Giraffa camelopardalis

6

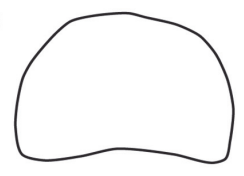

FIGURE 6. Representative cross sections of right metacarpals. 1, Helladotherium duvernoyi, late Miocene, Pikermi, MNHNP 1527; 2, Birgerbohlinia schaubi, late Miocene, Samos, AMNH 20610 (reversed); 3, Okapia johnstoni, AMNH 15218 (reversed); 4, Samotherium major, late Miocene, Samos, AMNH 22790; 5, Bohlinia attica, late Miocene, Pikermi, PA 1474-1991; 6, Giraffa camelopardalis, AMNH 70016. Scale bar equals $80 \mathrm{~mm}$.

eral ridge and a longitudinally oriented head (Figure 4). There is a narrow, deep, obliquely oriented groove on the lateral aspect of the lateral epicondyle, which appears to continue down the lateral aspect of the proximal shaft. The medial epicondyle is circle-sector shaped and flatter, and it is separated from the medial ridge (Figure 12.1). There is a wide and shallow groove on the medial aspect of the medial epicondyle, which ends distally in the central trough. There is a deep, narrow groove that separates the medial and lateral epicondyles and continues onto the central trough. The medial ridge is sharper and it flattens towards the distal shaft, whereas the lateral ridge is rounder, and it also flattens towards the distal shaft. There is an elongated oval fossa on the lateral aspect of the lateral ridge. The central trough is intermediate-deep in depth proximally, and becomes progressively shallower and is flat distally (Figure 6.4). The pyramidal rise present, most noticeably on the proximal shaft. The lateral aspect of the lateral distal condyle flares strongly and terminates at a distinct pointed bulge, whereas the medial aspect of the medial distal condyle is more vertical. The keels of the distal condyles extend onto the distal shaft, and they likely extend outside the synovial cavity.

Genus PALAEOTRAGUS Gaudry, 1861

\section{Selected Metacarpal Features B}

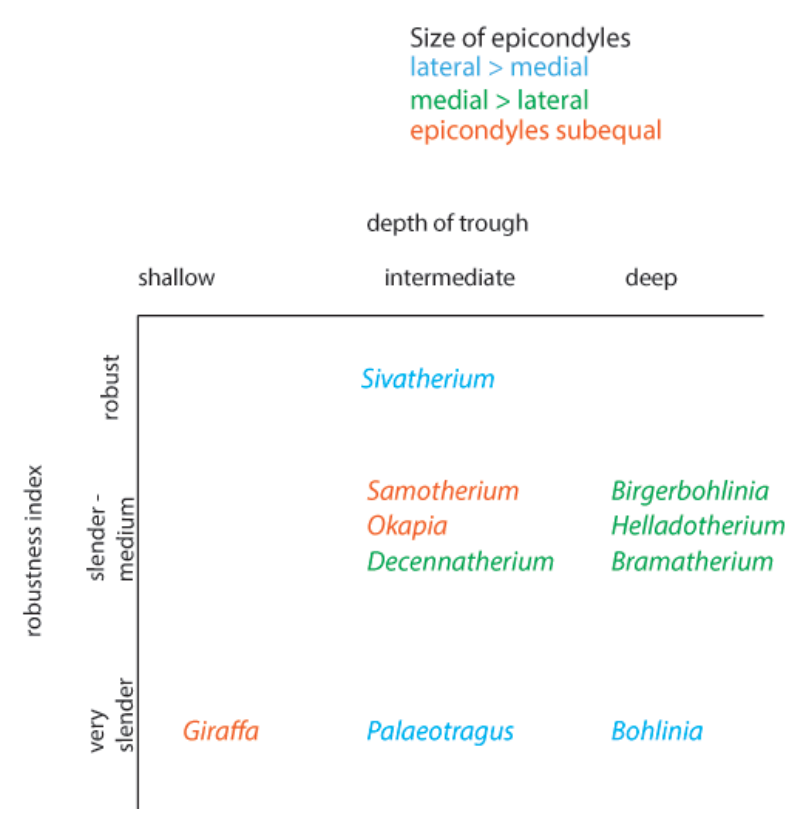

FIGURE 7. Three additional metacarpal characteristics. This simplified table can be used to facilitate specimen identifications and differentiate between different giraffid taxa. 

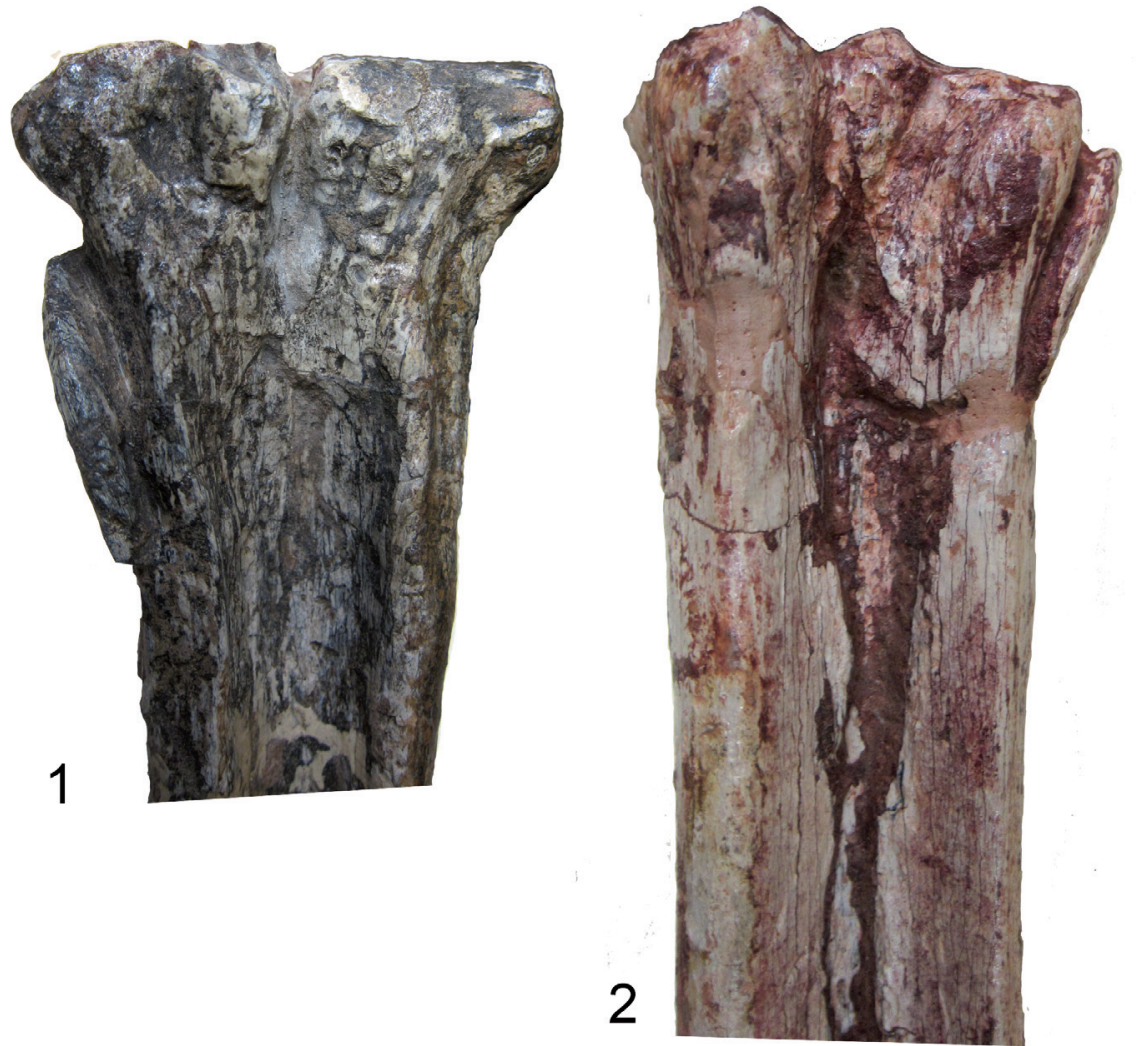

FIGURE 8. Bramatherium megacephalum from the Upper Siwaliks. 1, Right metacarpal AMNH 29820; 2, Right metatarsal AMNH 19688.
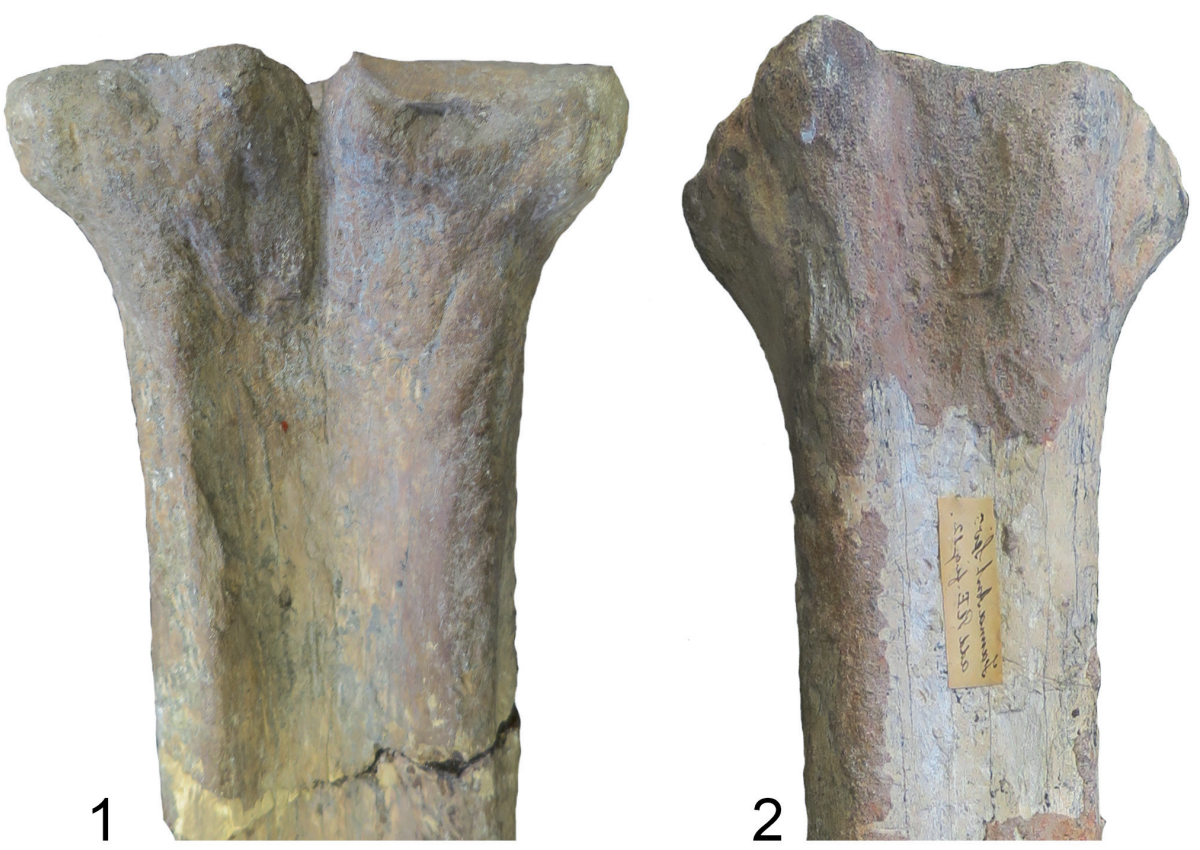

FIGURE 9. Sivatherium giganteum from the Upper Siwaliks. 1, Right metacarpal NHM UK 39533; 2, Left metatarsal (reversed) NHM UK 39752. 


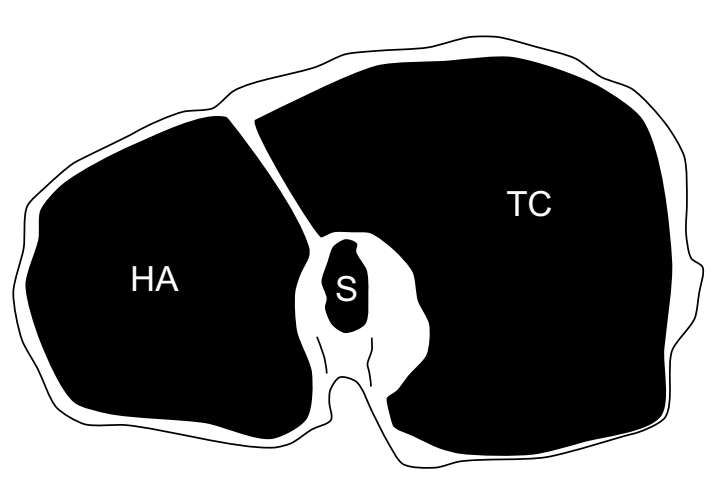

FIGURE 10. Metacarpal proximal morphology. Birgerbohlinia schaubi, late Miocene, Samos, AMNH 20610. Abbreviations: HA, os hamatum facet; TC, os trapezoideocapitatum facet; S, synovial fossa. Image not to scale.

Type species. Palaeotragus rouenii Gaudry, 1861 Palaeotragus rouenii Gaudry, 1861

\section{Specimen. MNHN PIK1692}

Description. The proximal articular surface is all on the same plane. The medial and lateral epicondyles are asymmetrical in size and morphology. There is an elongated oval fossa laterally, separating the lateral epicondyle into two heads. There is a triangular extension of the articular surface onto the lateral epicondyle. The distal edge of the lateral epicondyle continues onto the lateral ridge. The medial epicondyle is smaller and rectangular shaped (Figure 7). The surface is fuller and has a slight depression on the palmar surface, and the distal aspect continues onto the medial ridge. The lateral ridge is sharp and the medial ridge is rounded. The medial ridge is thickest and fullest proximally and becomes more confined throughout the shaft (Figure 12.2). There is a confined oval fossa on the lateral aspect of the lateral ridge. The central trough is intermediate in depth throughout the proximal and midshaft, and flattens towards the distal condyles. The medial and lateral ridges are very thin. They extend almost the entire length of the shaft and flatten close to the distal condyle. The pyramidal rise is present and faint at the distal shaft. The keels of the distal condyle extend onto the palmar shaft.

Genus BOHLINIA Matthew, 1929

Type species. Camelopardalis attica (Gaudry and Lartet, 1856)

Bohlinia attica (Gaudry and Lartet, 1856)

Specimens. MNHN PIK 27561 (figured in Gaudry, 1861: plate XL), NHM 11405, NHM M 11401, MNHN MAR3257, MNHN PIK11403
Description. The proximal articular surface is all on the same plane. The synovial fossa is closed and very small. The medial and lateral epicondyles are separated by a minimal step. The medial and lateral epicondyles are symmetrical in size. The medial epicondyle has a confined, horizontally oval fossa just distal to the articular surface. The lateral epicondyle is square shaped and extends distally onto the lateral ridge (Figure 13). The lateral epicondyle exhibits a distinct, triangular extension of the articular surface. There is a depression on the proximal, medial shaft which extends to the palmar midline, disrupting the continuity of the medial ridge with the medial epicondyle (Figure 14.2). The proximal shaft flares on the lateral edge and is straighter on the medial edge. There is a small, deep groove that separates the lateral and medial epicondyles, and does not continue onto the proximal shaft. The lateral ridge thickens around onethird of the length of the metapodial. The medial ridge is rounded and the lateral ridge sharp, creating a deep central trough (Figure 6.5). The medial ridge is rounded proximally, and becomes progressively flatter distally, whereas the lateral ridge remains sharp throughout the length. The pyramidal rise is absent. The medial ridge exhibits a strong, elongated oval fossa on the medial edge, whereas the lateral ridge exhibits a faint, elongated oval fossa on the lateral edge (Figure 4). The distal epiphysis is slightly broader than the remainder of the shaft. The keels of the distal condyles extend onto the palmar distal shaft.

\section{Genus GIRAFFA Brisson, 1756}

Type species. Cervus camelopardalis (Linnaeus, 1758)

Giraffa camelopardalis (Linnaeus, 1758)

Specimens. AMNH 53543, AMNH 82001, AMNH 53550

Description. The proximal articular surface is all on the same plane. The synovial fossa is closed. The medial and lateral epicondyles are symmetrical in size and morphology (Figure 15). The proximal articular surface extends on to the palmar surface of the lateral epicondyle. Directly distal to this, there is a horizontal, deep groove. The medial epicondyle is relatively square while the lateral epicondyle is triangular in shape (Figure 14.3). There is a shallow depression on the proximal end of the medial epicondyle. The central area between the medial and lateral epicondyles is textured with many ridges, foramina, and grooves. There is a shallow groove that separates the medial and lateral epicondyles, and it continues onto the central 

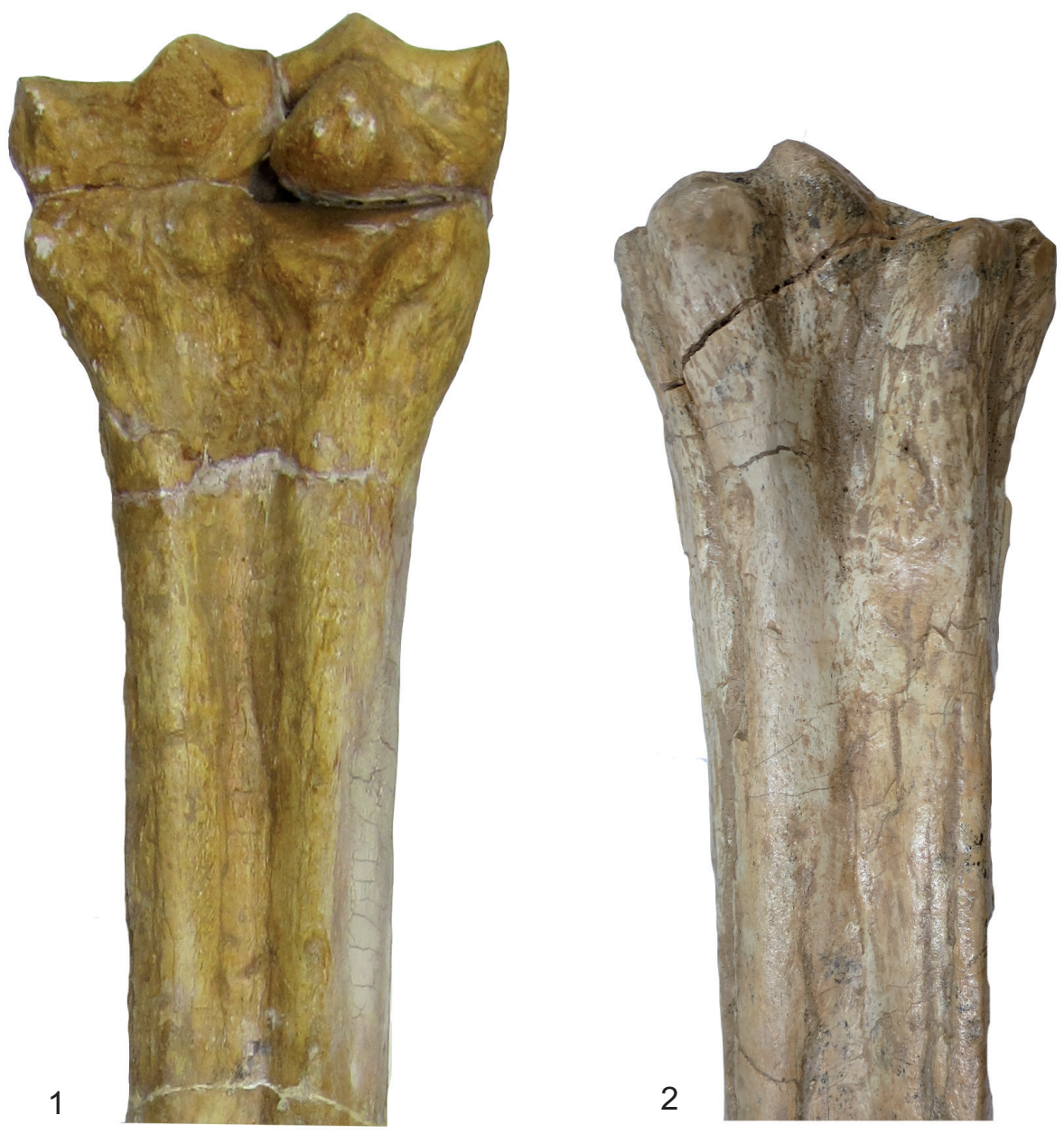

FIGURE 11. Samotherium major from Samos. 1, Right metacarpal NHMBe 711; 2, Right metatarsal AMNH 22967.

trough. The distal edge of the medial and lateral epicondyles extends onto the medial and lateral ridges, respectively. The central trough is shallow in depth (Figure 6.6). The medial and lateral ridges are both sharp and thin. They flatten on the distal third of the shaft. The pyramidal rise on the distal aspect of the shaft is very faint. There is a shallow central groove on the palmar distal shaft. The medial edge of the shaft flares towards the distal condyle. The keels of the distal condyles are confined, and do not extend onto the distal shaft.

\section{Description of the metatarsals of Giraffidae}

Genus Canthumeryx Hamilton, 1973

Type species. Canthumeryx sirtensis Hamilton, 1973

Canthumeryx sirtensis Hamilton, 1973
Specimen. KNM-MO 41

Description. The medial and lateral epicondyles are asymmetrical in size and morphology. The medial epicondyle is large with a rectangular and flat surface. The lateral epicondyle is more confined, is triangular-shaped, and is more protruding proximally (Figure 14.1). There is a wide deep groove between the lateral aspect of the lateral epicondyle and the shaft, separating it into two distinct heads that flare outward. There is wide, deep groove between the medial aspect of the medial epicondyle and the shaft, separating it into two distinct heads that strongly flare outward, notably on the dorsal head (Figure 16). The pygmaios is pointed, protrudes proximally, and is oriented longitudinally. It has a stronger connection with the medial epicondyle. There is a fossa in the proximal plantar surface with a sharp medial wall and a 


\section{Samotherium major}

1

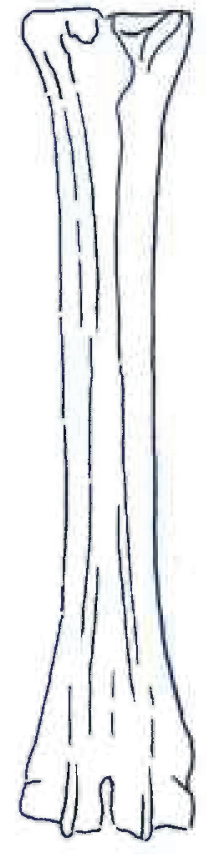

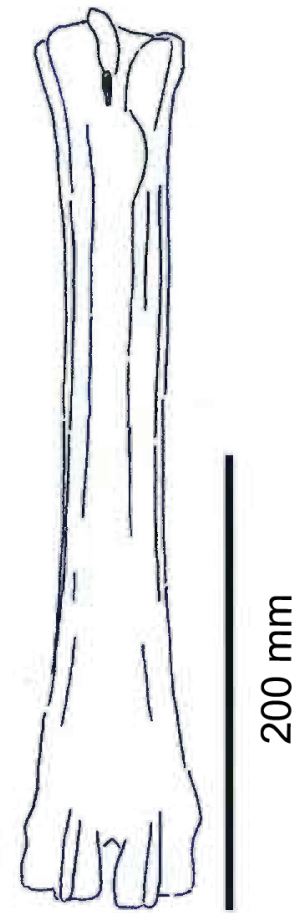

Palaeotragus rouenii

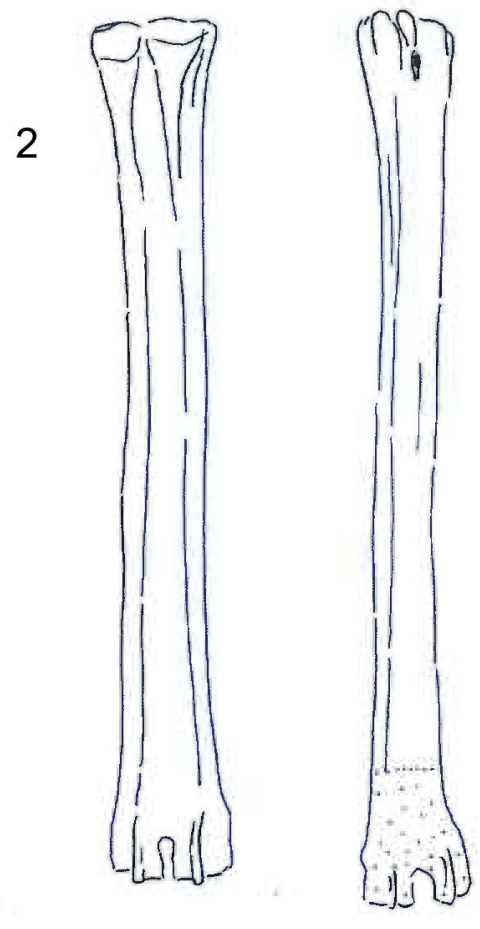

FIGURE 12. Palmar views of the right metacarpals (left) and plantar views of the metatarsals (right) of certain Giraffidae. 1, Samotherium major, late Miocene, Samos, NHM Be Samos 711 (metacarpal), AMNH 22967 (metatarsal) (both reversed); 2, Palaeotragus rouenii, late Miocene, Pikermi, MNHNP 1692 (metacarpal), (reversed); MNHNP 1691 (metatarsal). Scale bar equals $200 \mathrm{~mm}$.

rounded lateral wall. The medial and lateral ridges are broad and flat, creating a very narrow, intermediate in depth central groove (Figure 17). The lateral ridge is more rounded than the medial ridge.

Genus HELLADOTHERIUM Gaudry, 1861

Type species. Camelopardalis duvernoyi (Gaudry and Lartet, 1856)

Helladotherium duvernoyi Gaudry, 1861

Specimens. MNHN PIK1564, M 11381

Description. The proximal articular surface exhibits three distinct facets: the lateral facet for the os naviculocuboideum is kidney-shaped. The medial facet for the os cuneiforme intermediolaterale is sub-triangular and is not contacting the os cuneiforme mediale facet, which is oval (Figure 18.1). The medial and lateral epicondyles are symmetrical in size and morphology (Figure 3). There is a deep groove running obliquely on the lateral shaft, separating the lateral epicondyle into plantar and dorsal heads. The plantar head has a rounded sur- face which is continuous distally with the lateral ridge. The medial epicondyle is split into two heads by a shallow, obliquely oriented groove on the medial shaft. The plantar head has a full, rounded, elevated surface which is continuous with the medial ridge. In both the medial and lateral epicondyles, the plantar head is oriented longitudinally and the dorsal head flares outward. The medial and lateral epicondyles are separated by a wide, flattened groove. There is no distinct pygmaios (Figure 16). There is an oval, elongated bony protrusion on the medial shaft, which protrudes proximally onto the proximal articular surface. The medial ridge has a secondary elevated ridge on the inner surface. The central trough is deep (Figure 5.1). The pyramidal rise is prominent on the distal shaft and faint at the midshaft. The keels of the distal condyle are confined and do not extend onto the plantar shaft.

Genus BRAMATHERIUM Falconer, 1845 

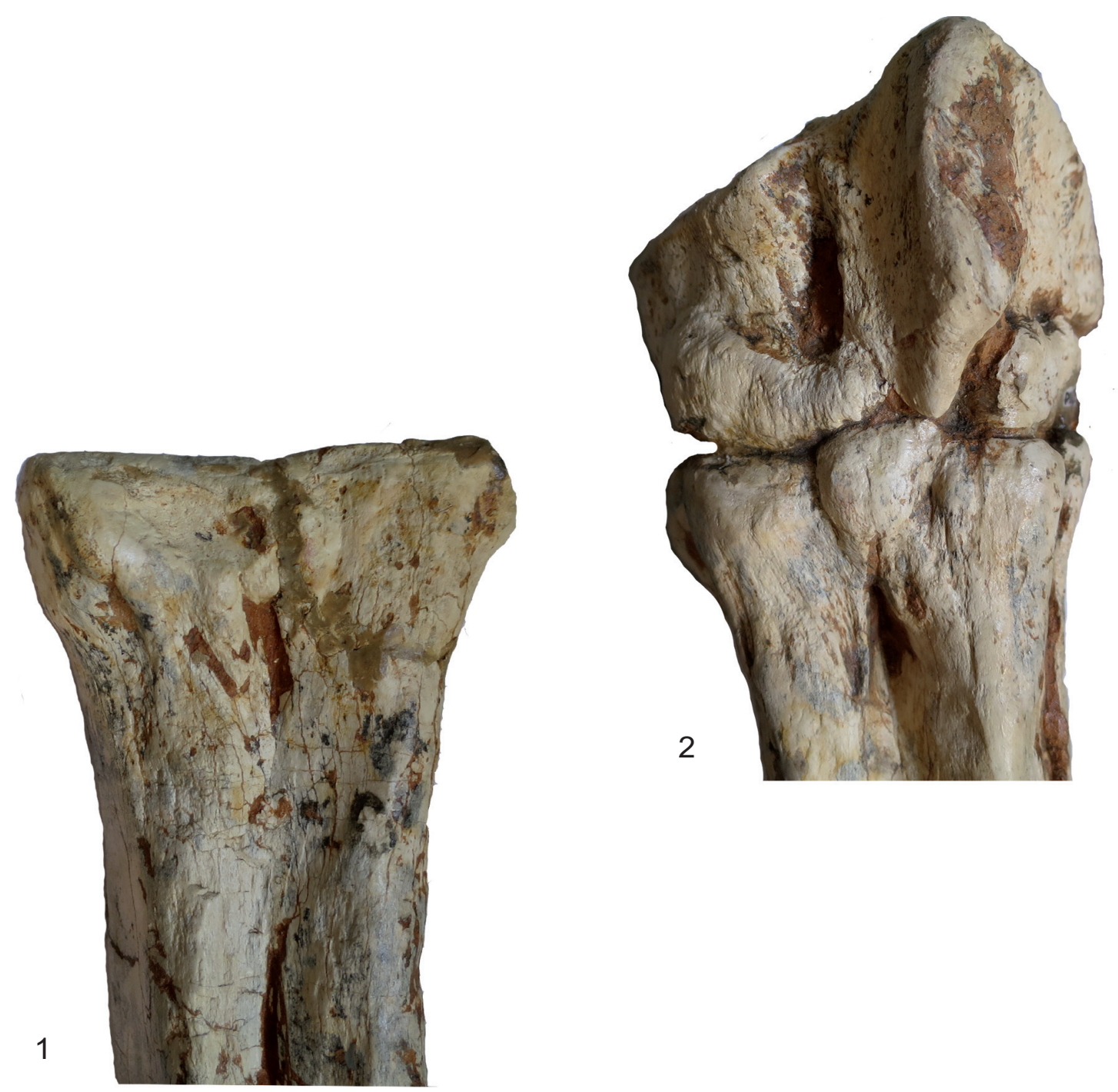

FIGURE 13. Bohlinia attica from Pikermi. 1, Right metacarpal MNHN 52780; 2, Right metatarsal MNHN 1639.

Type species. Bramatherium perimense Falconer, 1845

Bramatherium megacephalum Lydekker, 1876

Specimen. AMNH 19688

Description. The proximal articular surface exhibits three distinct facets. The lateral facet for the os naviculocuboideum is oval-shaped. The medial facet for the os cuneiforme intermediolaterale is semicircular in shape and is not contacting the os cuneiforme mediale facet (Figure 18.2). The medial epicondyle is split into a dorsal and plantar head by a longitudinal groove on the medial shaft (Figure 5.2). The plantar head is small with a rounded surface, and the distal aspect continues onto the medial ridge. The lateral epicondyle is split into a dorsal and plantar head by a longitudinal groove on the lateral shaft. The plantar head is more expansive and triangular with a flattened surface, and is continuous distally with the lateral ridge. Both heads of the lateral and medial epicondyles are oriented longitudinally, however the dorsal heads slightly flare outward (Figure 16). On the proximal medial shaft, there is a small circular bony protrusion separated from the rest of the shaft by a narrow groove (Figure 8). This is confined to the proximal shaft and is visible at the medial proximal articular surface (Figure 17). At the proximal lateral shaft, there is a large oval bony protrusion, which is completely separated from the lateral epicondyle and shaft. It is oriented obliquely towards the plantar shaft. The pygmaios is rounded and oriented towards the medial side (Figure 16). The medial and lateral ridges are sharp. The central trough is 
Bohlinia attica

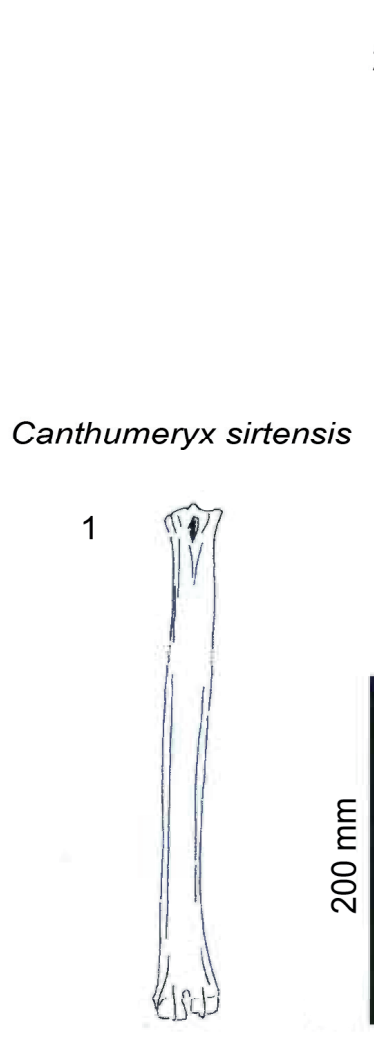

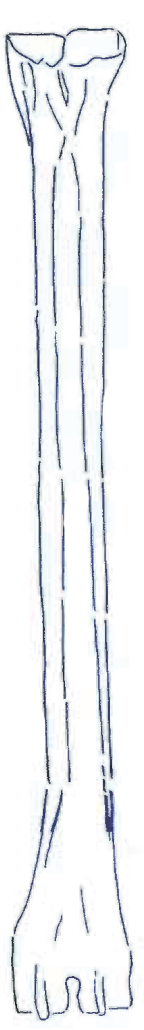

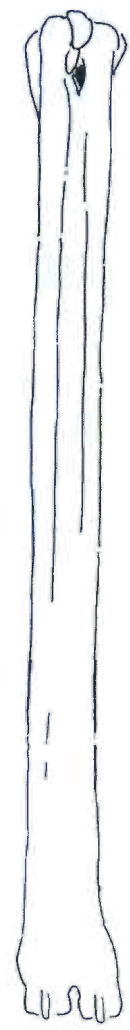

Giraffa camelopardalis

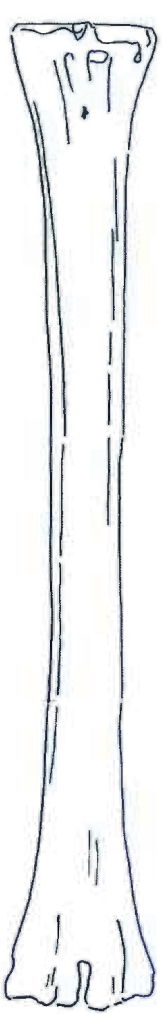

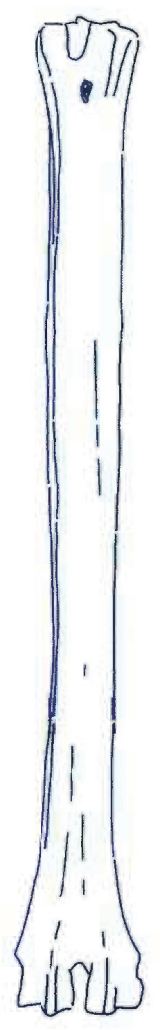

FIGURE 14. Palmar views of the right metacarpals (left) and plantar views of the metatarsals (right) of certain Giraffidae. 1, Canthumeryx sirtensis, early-middle Miocene, Moruorot Hill, NMK Mo 41 (metatarsal); 2, Bohlinia attica, late Miocene, Pikermi, MNHNP 27561 (metacarpal), MNHNP 2357 (metatarsal) (reversed); 3, Giraffa camelopardalis, Zaire, AMNH 53550 (metacarpal), AMNH 53550 (metatarsal) (both reversed). Scale bar equals $200 \mathrm{~mm}$.

intermediate in depth, and it flattens at the distal shaft. The distal shaft flares laterally. The keels of the distal condyles extend onto the distal shaft medially, but are confined laterally.

Genus SIVATHERIUM Falconer and Cautley, 1836

Type species. Sivatherium giganteum Falconer and Cautley, 1836

Sivatherium giganteum Falconer and Cautley, 1836

Specimens. NHM UK 39752, NHM UK 39753

Description. The proximal articular surface exhibits three distinct facets. The lateral facet for the os naviculocuboideum is kidney-shaped. The medial facet for the os cuneiforme intermediolaterale is half-moon shaped and contacts the os cuneiforme mediale facet in a small point. The lateral epicondyle is larger with a flatter surface. It is divided into a plantar and a dorsal head by a deep longitudi- nally oriented groove (Figure 5.3). The plantar head is oriented longitudinally, and the dorsal head flares outward (Figure 16). The medial epicondyle protrudes more due to a circular bony protrusion on the plantar surface (Figure 17). It is split into a plantar and a dorsal head by a shallow, wide groove on the medial shaft. Both heads slightly flare outward (Figure 9). The medial and lateral epicondyles are separated by a wide, flattened groove. There is no discernible pygmaios. The medial and lateral ridges are very rounded and small, creating a flattened central trough. The distal shaft flares outward, notably on the lateral edge. There is no visible pyramidal rise. The keels of the distal condyles slightly extend onto the plantar surface of the distal shaft.

Genus DECENNATHERIUM Crusafont, 1952

Type species. Giraffinae? pachecoi (Crusafont, 1952) 

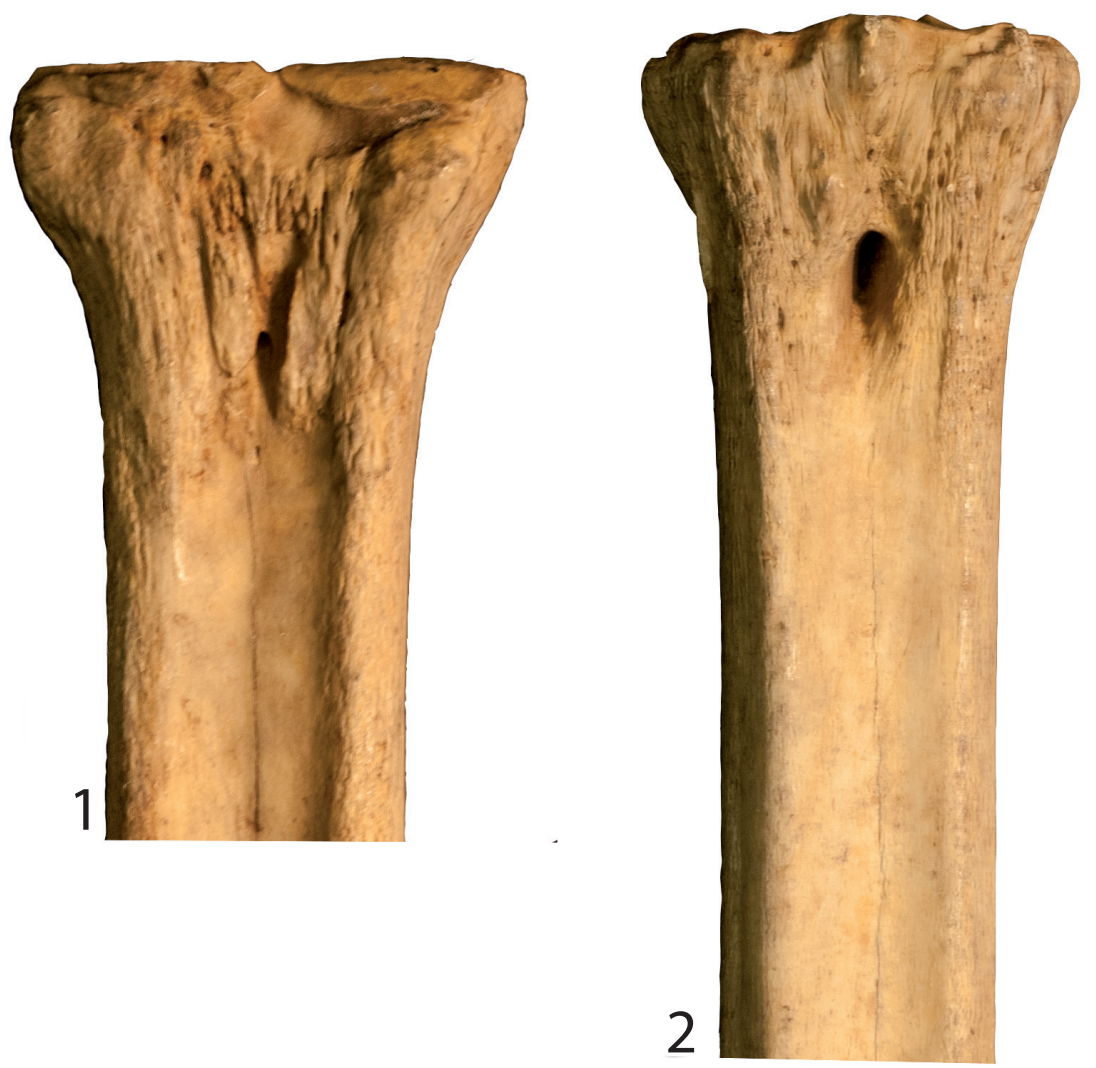

FIGURE 15. Giraffa camelopardalis from Kenya. 1, Left metacarpal (reversed) AMNH 53543; 2, Left metatarsal (reversed) AMNH 53550.

Decennatherium pachecoi Crusafont, 1952

Specimens. MNCN 42765, MNCN 42768, MNCN 42764, MNCN 42767, MNCN 42766, MNCN 42778, MNCN 42770

Description. The proximal articular surface exhibits three distinct facets: the facet for the os naviculocuboideum (lateral) is kidney-shaped, and the facet for the os cuneiforme intermediolaterale (medial) is half-moon shaped. The os cuneiforme mediale facet is oval and touches the os cuneiforme intermediolaterale facet in one point (Figure 18.3). On the lateral facet, there is a distinct constriction where the lateral ridge meets the lateral epicondyle. The medial and lateral epicondyles are asymmetrical in size, the medial being more prominent (Figure 5.4). The medial epicondyle is separated into a plantar and a dorsal head by a longitudinal groove that continues down the medial aspect of the shaft. Both heads slightly flare out- ward. The lateral epicondyle is separated into a dorsal and plantar head by a notably deep, wide groove. The plantar head is oriented longitudinally and the dorsal head flares outward. The pygmaios presents as a distinct, oval protrusion with a rounded surface, which is oriented medially and protrudes proximally (Figure 16). There is a bony protrusion on the medial surface of the medial epicondyle. The medial and lateral ridges originate at the distal aspect of the plantar heads of the medial and lateral epicondyles. There is a deep groove that separates the medial and lateral epicondyles, which continues onto the central trough. The medial and lateral ridges continue to just proximal to the distal condyles, where they abruptly flatten. The central trough is intermediate to shallow in depth (Figure 17) and flattens at the distal aspect of the shaft. The medial ridge is rounder than the lateral ridge. The distal shaft flares laterally. The 
Selected Metatarsal Features A

Orientation of pygmaios: longitudinal

medially

absent

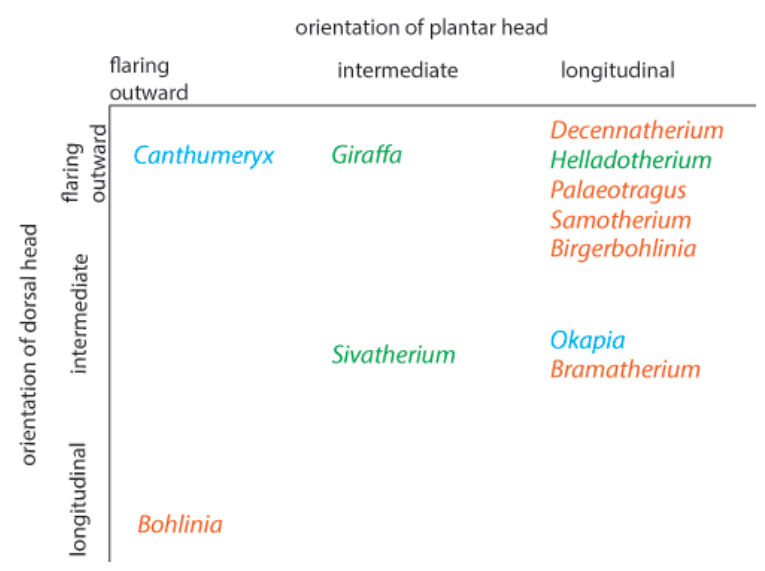

FIGURE 16. Three selected metatarsal characteristics. This simplified table can be used to facilitate specimen identifications and differentiate between different giraffid taxa.

keels of the distal condyle continue slightly onto the plantar shaft.

Genus BIRGERBOHLINIA Crusafont, 1952

Type species. Birgerbohlinia schaubi Crusafont, 1952

Birgerbohlinia schaubi Crusafont, 1952

Specimens. IPS 5015, IPS 5090, IPS 4981, MGUV 7788, MGUV 7803

Description. The proximal articular surface exhibits three distinct facets. The facet for the os naviculocuboideum is kidney-shaped. The facet for the os cuneiforme intermediolaterale is more oval and is separated from the os cuneiforme mediale facet, which is more triangular (Figure 18.4). The medial and lateral epicondyles are asymmetrical in size and morphology (Figure 5.5). The medial epicondyle is only slightly split into two heads by a shallow, obliquely oriented groove on the medial shaft. The plantar head has a full, rounded, elevated surface which is continuous with the medial ridge. There is a deep groove running obliquely on the lateral shaft, separating the lateral epicondyle into plantar and dorsal heads. The plantar head has a rounded surface which is continuous distally with the lateral ridge. In both the medial and lateral epicondyles, the plantar head is oriented longitudinally and the dorsal head flares outward (Figure 16).
Selected Metatarsal Features B

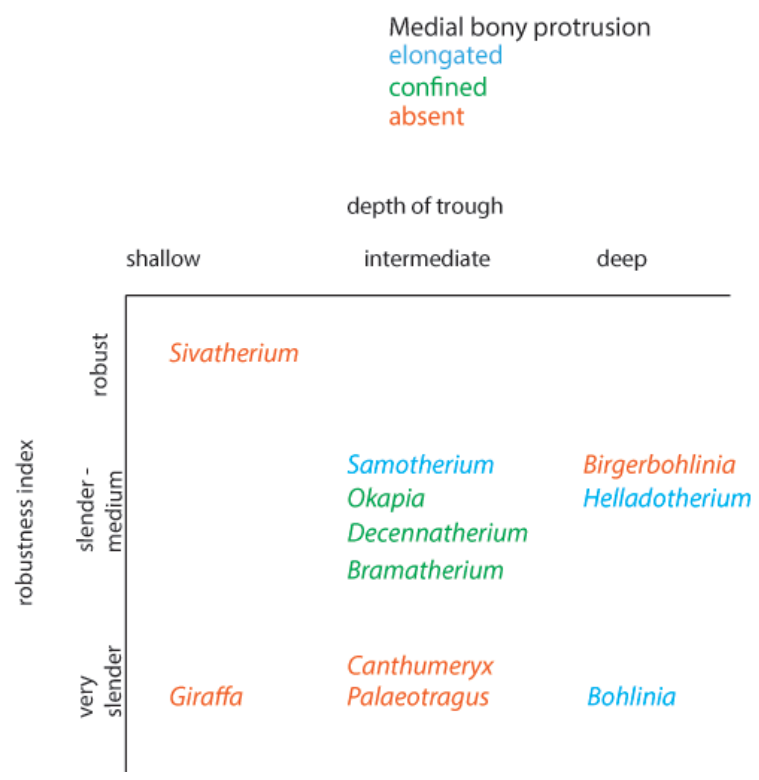

FIGURE 17. Three selected metatarsal characteristics. This simplified table can be used to facilitate specimen identifications and differentiate between different giraffid taxa.

The medial and lateral epicondyles are separated by a wide, deep groove. The lateral ridge is sharp, whereas the medial ridge is rounded. The central trough is very deep (Figure 17). The keels of the distal condyles slightly extend onto the distal shaft.

Genus OKAPIA Lankester, 1901

Type species. Equus johnstoni (Sclater, 1901)

Okapia johnstoni Lankester, 1901

Specimens. AMNH 51196, AMNH 51107, AMNH 51218

Description. The proximal articular surface exhibits three distinct facets. The lateral facet for the os naviculocuboideum is kidney-shaped. The medial facet for the os cuneiforme intermediolaterale is more oval and is not contacting the os cuneiforme mediale facet. On the lateral facet, there is a distinct constriction where the lateral ridge meets the lateral epicondyle. The medial epicondyle is significantly fuller and protrudes more than the lateral side (Figure 5.6). This is due to a large, circular bony protrusion on the plantar surface of the medial epicondyle. A wide, shallow groove separates the medial epicondyle into a dorsal and a plantar head, both of which are oriented longitudinally. There is a confined groove on the lateral 
1

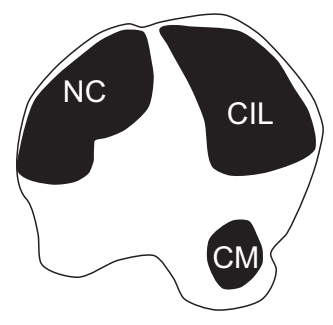

2

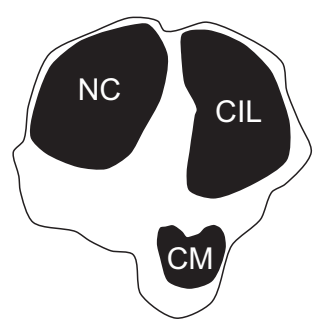

3

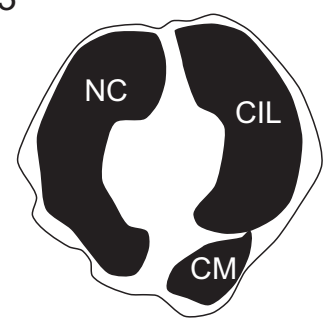

4

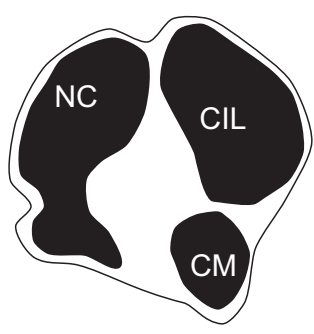

FIGURE 18. Metatarsal proximal morphology. 1, Helladotherium duvernoyi, late Miocene, Pikermi, M 1138; 2, Bramatherium megacephalum, late Miocene-Pliocene, Siwaliks, AMNH 19688; 3, Decennatherium pachecoi, late Miocene, Los Valles de Fuentidueña, MNCN 42764; 4, Birgerbohlinia schaubi, late Miocene, Piera, IPS 5090. Abbreviations: NC, os naviculocuboideum facet; CIL, os cuneiforme intermediolaterale facet; $\mathbf{C M}$, os cuneiforme mediale facet. Images not to scale.

aspect of the lateral epicondyle, separating it into a plantar and a dorsal head. The plantar head is oriented longitudinally with the shaft, and the dorsal head slightly flares outward. There is a very shallow and wide groove between the medial and lateral epicondyle. The pygmaios is a notably reduced, flat, rounded protrusion between the medial and lateral epicondyles that does not protrude proximally (Figure 16). Medial to the medial epicondyle, there is a confined, oval bony extension running longitudinally (Figure 17). This extends just distal to the proximal articular surface. The central trough is intermediate in depth, and it flattens distally. The medial and lateral ridges are sharp and thin. There is a distinct pyramidal rise on the distal shaft. The keels of the distal condyle extend onto the distal shaft, outside the synovial cavity.

Genus SAMOTHERIUM Forsyth Major, 1888

Type species. Samotherium boissieri Forsyth Major, 1888

\section{Samotherium major Bohlin, 1926}

Specimens. AMNH 22967, AMNH 22966

Description. The proximal articular surface exhibits three distinct facets. The lateral facet for the os naviculocuboideum is kidney-shaped. The medial facet for the os cuneiforme intermediolaterale is half-moon shaped and contacts the os cuneiforme mediale facet in a small point. On the lateral facet, there is a distinct constriction where the lateral ridge meets the lateral epicondyle. There is a bony protrusion medial to the separation of the large and small medial facets. The medial and lateral epicondyles are asymmetrical in size (Figure 11). The lat- eral epicondyle is larger and has a fuller surface (Figure 12.1). The medial epicondyle is separated into a plantar and a dorsal head by a longitudinal groove that continues down the medial aspect of the shaft. Both heads slightly flare outward (Figure 16). The lateral epicondyle is separated into a dorsal and plantar head by a notably deep, wide groove. The plantar head is oriented longitudinally and the dorsal head flares outward. There is an elongated oval bony protrusion at the proximal medial shaft, which originates at the level of the proximal articular surface (Figure 17). The medial and lateral ridges originate at the distal aspect of the plantar heads of the medial and lateral epicondyles. There is a deep groove that separates the medial and lateral epicondyles, which continues onto the central trough. The pygmaios is distinct from the proximal shaft by deep medial and lateral grooves, is rounded, curves medially, and protrudes proximally (Figure 16). The medial and lateral ridges continue to just proximal to the distal condyles, where they abruptly flatten. They are both sharp. The central trough is intermediate in depth and flattens at the distal aspect of the shaft. The distal shaft flares laterally. The keels of the distal condyle continue slightly onto the plantar shaft.

$$
\text { Genus PALAEOTRAGUS Gaudry, } 1861
$$

Type species. Palaeotragus rouenii Gaudry, 1861

$$
\text { Palaeotragus rouenii Gaudry, } 1861
$$

Specimens. MNHN PIK1690, MNHN PIK1690

Description. There is a circular, full protrusion at the articular surface above the lateral dorsal facet, and a pointed protrusion between this and the ventro-medial circular facet. The medial and lateral 
epicondyles are similar in size and morphology (Figure 12.2). There is an obliquely oriented groove between the lateral aspect of the lateral epicondyle and the shaft, separating it into a distinct dorsal and plantar head. The dorsal head flares outward and the plantar head is oriented longitudinally (Figure 16). There is an obliquely oriented groove between the medial aspect of the medial epicondyle and the shaft, separating it into two distinct heads. The dorsal head flares outward and the plantar head is oriented longitudinally. Both plantar heads of the medial and lateral epicondyles are rounded, full, and are continuous longitudinally with the medial and lateral ridges. The pygmaios is oriented medially, is compressed and protrudes proximally (Figure 16). It is more connected to the lateral facet, and the tip is rounded. The central trough is intermediate in depth and flattens at the distal shaft (Figure 17). Both medial and lateral ridges are sharp and thin. The keels of the distal condyle extend onto the distal shaft.

\section{Genus BOHLINIA Matthew, 1929}

Type species. Camelopardalis attica (Gaudry and Lartet, 1856)

\section{Bohlinia attica (Gaudry and Lartet, 1856)}

Specimens. MNHN PIK2357, MNHN SLQ682

Description. The medial and lateral epicondyles are symmetrical in size and morphology (Figure 13). The medial epicondyle has a deep longitudinal groove on the medial aspect, separating it into a dorsal and a plantar head oriented longitudinally. The lateral epicondyle has a deep longitudinal groove on the lateral aspect that separates the lateral epicondyle into a distinct dorsal and plantar head, which are oriented longitudinally (Figure 14.2). Both the medial and lateral epicondyles are long and flat, and they connect distally to the medial and lateral ridges. The pygmaios is fused to the central aspect of the medial epicondyle, separated by a short, deep groove. It is oriented medially and is flat proximally (Figure 16). There is an elongated, flattened bony protrusion on the medial shaft that originates at the proximal articular surface (Figure 17). The lateral ridge is sharp, whereas the medial ridge is rounded. The central trough is deep and flattens just proximal to the distal condyles. At the distal shaft, there are four shallow grooves, separating the distal end into four fused heads. The keels of the distal condyles are confined and do not extend onto the distal shaft.

\section{Genus GIRAFFA Brisson, 1756}

Type species. Cervus camelopardalis (Linnaeus, 1758)

Giraffa camelopardalis (Linnaeus, 1758)

Specimens. AMNH 53543, AMNH 82001, AMNH 53550, AMNH 14135

Description. The proximal articular surface exhibits three distinct facets. The lateral facet for the os naviculocuboideum is kidney-shaped. The medial facet for the os cuneiforme intermediolaterale is more oval and can be contacting or slightly separated from the os cuneiforme mediale facet, which is oval. On the lateral facet, there is a slight constriction where the lateral ridge meets the lateral epicondyle. Medial to this constriction, there is a pointed bony protrusion on the articular surface. The medial and lateral epicondyles are symmetrical in size and morphology (Figure 15). There is a shallow, obliquely oriented groove on the medial edge of the medial epicondyle, separating it into a plantar and a dorsal head. Both heads slightly flare outward (Figure 14.3). There is a deep, oblique groove on the lateral epicondyle, separating the lateral epicondyle into a plantar and a dorsal head. Both heads flare outward, and the flaring is more pronounced on the dorsal head. The pygmaios is absent, there is a dish-shaped depression on the plantar surface between the medial and lateral epicondyles with lipped, distinct edges in its place (Figure 16). There is a thin, elongated, oval bony protrusion on the medial surface of the medial epicondyle (Figure 17). The central trough is shallow in depth, and flattens distally. The medial and lateral ridges are sharp and thin. On the lateral and medial surfaces, the lateral and medial ridges appear more textured than the main shaft. There is a faint pyramidal rise distally. The medial edge of the shaft flares towards the distal condyle. The keels of the distal condyle are confined and do not extend onto the distal shaft.

\section{Comparisons between the metacarpals}

To analyze the proportions of the metacarpals we have used the robustness index (RI) (Fragomeni and Prothero, 2011; Woodman and Gaffney, 2014).

We have applied this formula to a sample of a total 115 giraffid metacarpals and established the following robustness categories (Figure 19; Tables 1-2):

1. Very slender: RI under 9. Includes Bohlinia attica, Giraffa camelopardalis, Canthumeryx sirtensis, and Palaeotragus rouenii.

2. Slender: 


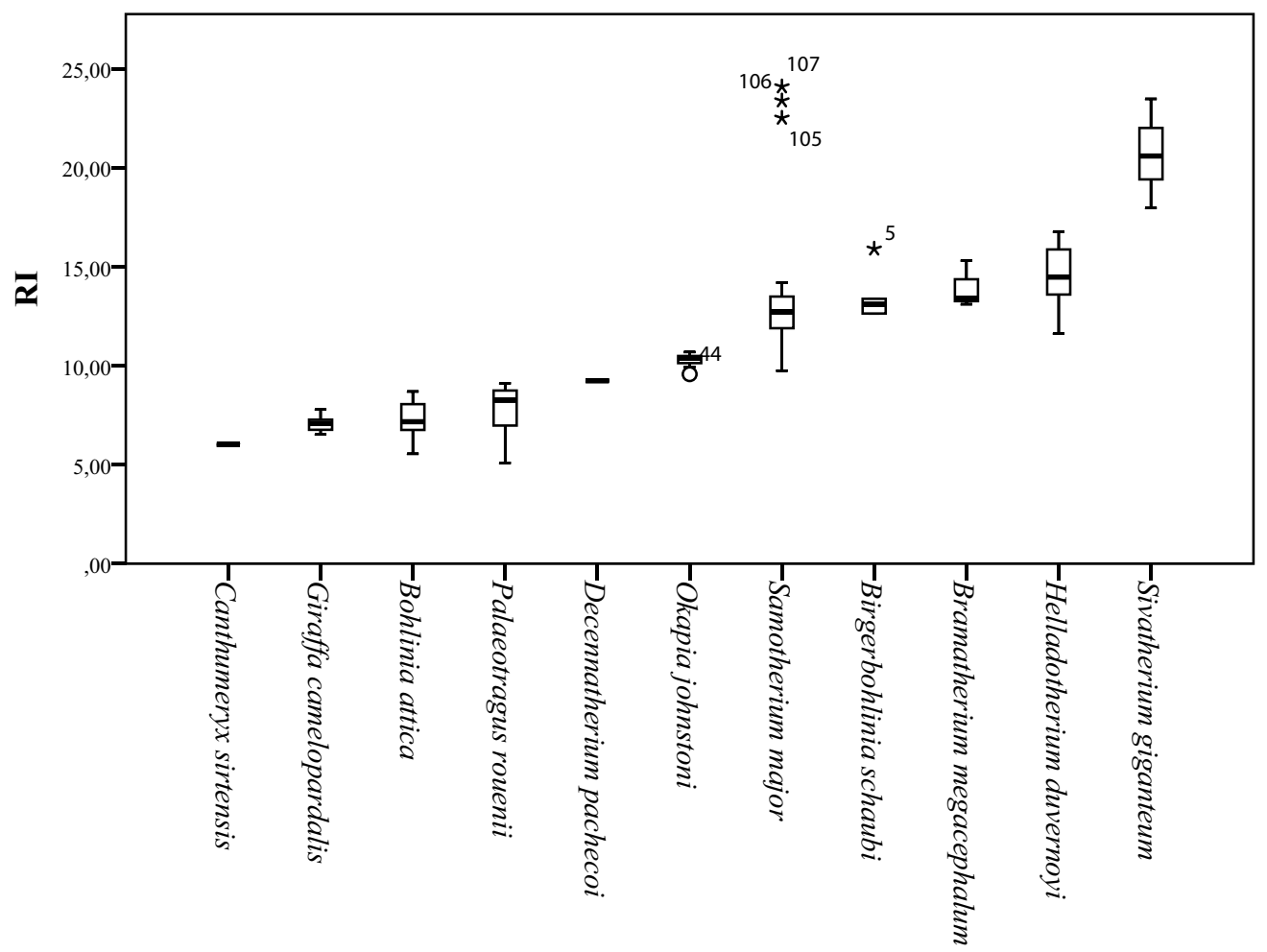

FIGURE 19. Box-and-whiskers plot with the metacarpal RI of the Giraffidae analyzed.

3. RI between 9 and 10. Includes Okapia johnstoni and Decennatherium pachecoi.

4. Medium: RI between 10 and 17. Includes Bramatherium megacephalum, Samotherium major, Birgerbohlinia schaubi, and Helladotherium duvernoyi.

5. Robust: RI over 17. Includes Sivatherium giganteum.

We have also analyzed the variation in length of a sample of 142 giraffid metacarpals and established the following categories (Figure 20; Tables 1, 3):

1. Long: $>500 \mathrm{~mm}$, includes Bohlinia attica and Giraffa camelopardalis.

2. Medium: between 500 and $350 \mathrm{~mm}$, most species fall into this category. Birgerbohlinia schaubi, Sivatherium giganteum, Decennatherium pachecoi, and Palaeotragus rouenii fall into the medium-short range, with most specimens between 350 and $450 \mathrm{~mm}$, while Bramatherium megacephalum, Helladotherium duvernoyi, and Samotherium major fall into the medium-long category, with most specimens over $450 \mathrm{~mm}$.

3. Short: $<350 \mathrm{~mm}$ Canthumeryx sirtensis and
Okapia johnstoni fall in this category.

Using these descriptive parameters, we also plot the total length versus the midshaft minimum transverse diameter, to demonstrate the relative slenderness of the limbs (Figure 21) (Bover et al., 2010; Fragomeni and Prothero, 2011; Woodman and Gaffney, 2014).

\section{Comparisons between the metatarsals}

We have established the robustness categories using the same formula as above for the giraffid metatarsals ( $\mathrm{N}=92)$ (Figure 22; Tables 4-5):

1. Very slender: RI under 8 . Includes Bohlinia attica, Giraffa camelopardalis, Canthumeryx sirtensis, and Palaeotragus rouenii.

2. Slender: RI between 8 and 10. Includes Okapia johnstoni and Decennatherium pachecoi.

3. Medium: RI between 10 and 12. Includes Bramatherium megacephalum, Samotherium major, Birgerbohlinia schaubi, and Helladotherium duvernoyi.

4. Robust: RI over 12. Includes the robust Sivatherium giganteum.

We have also analyzed the variation in length of a sample of 110 giraffid metatarsals and estab- 
TABLE 1. Dimensions in mm of the metacarpal III-IV of Giraffidae (DT, transversal diameter; Diaph., diaphysis; RI, robustness index).

\begin{tabular}{|c|c|c|c|c|c|}
\hline Species & Specimen $n^{\circ}$ & $\begin{array}{c}\text { Total } \\
\text { Length }\end{array}$ & Diaph. TD & RI & Reference \\
\hline Canthumeryx sirtensis & UCB V.4899/42058 & 290 & 17,5 & 6,03 & Hamilton, 1978 \\
\hline Canthumeryx sirtensis & BU 20128 & 317 & & & Hamilton, 1973, 1978 \\
\hline Helladotherium duvernoyi & MNHN PIK1658 & 395 & 46 & 11,65 & \\
\hline Helladotherium duvernoyi & MNHN PIK1527 & 405 & 68 & 16,79 & \\
\hline Helladotherium duvernoyi & MNHN PIK1525 & 420 & 56 & 13,33 & \\
\hline Helladotherium duvernoyi & MNHN PIK1526 & 410 & 60 & 14,63 & \\
\hline Helladotherium duvernoyi & M 11382 & 408 & 56,61 & 13,88 & \\
\hline Helladotherium duvernoyi & M 11377 & 420 & 66,42 & 15,81 & \\
\hline Helladotherium duvernoyi & & 400 & & & Gaudry et al., 1873 \\
\hline Helladotherium duvernoyi & $1972 / 9$ & 420 & 67 & 15,95 & Melentis, 1974 \\
\hline Helladotherium duvernoyi & $1972 / 11$ & 413 & 65 & 15,74 & Melentis, 1974 \\
\hline Helladotherium duvernoyi & MNHN PIK-1525 & 427 & & & Geraads, 2009 \\
\hline Helladotherium duvernoyi & MNHN PIK-1526 & 410 & & & Geraads, 2009 \\
\hline Helladotherium duvernoyi & BMNH M 11382 & 418 & & & Geraads, 2009 \\
\hline Helladotherium duvernoyi & MNHN PIK-1527 & 407 & & & Geraads, 2009 \\
\hline Helladotherium duvernoyi & BMNH M 11377 & 426 & & & Geraads, 2009 \\
\hline Helladotherium duvernoyi & AMNH 20610 & 445 & 65,21 & 14,65 & \\
\hline Helladotherium duvernoyi & MTLA248 & 425 & & & Kostopoulos, 2009 \\
\hline Helladotherium duvernoyi & MTLA249 & 438 & 70 & 15,98 & Kostopoulos, 2009 \\
\hline Helladotherium duvernoyi & MNHN MAR916 & 455 & 54 & 11,87 & \\
\hline Helladotherium duvernoyi & MNHN MAR914 & 460 & 66 & 14,35 & \\
\hline Helladotherium duvernoyi & MNHN, sans numero & 465 & & & Geraads, 2009 \\
\hline Helladotherium duvernoyi & HD-5504 & 435 & & & Geraads, 2009 \\
\hline Helladotherium duvernoyi & HD-5492 & 430 & & & Geraads, 2009 \\
\hline Helladotherium duvernoyi & sans numero & 418 & & & Geraads, 2009 \\
\hline Helladotherium duvernoyi & sans numero & 435 & & & Geraads, 2009 \\
\hline Helladotherium duvernoyi & sans numero & 470 & & & Geraads, 2009 \\
\hline Helladotherium duvernoyi & & 408 & & & Geraads, 2009 \\
\hline Helladotherium duvernoyi & & 436 & & & Geraads, 2009 \\
\hline Helladotherium duvernoyi & MNHN FLUB824 & 410 & 58 & 14,15 & \\
\hline Helladotherium duvernoyi & & 410 & & & Gaudry et al., 1873 \\
\hline Bramatherium megacephalum & AM 29820 & 427 & 56 & 13,11 & Colbert, 1935 \\
\hline Bramatherium megacephalum & AM 19460 & 432 & 58 & 13,43 & Colbert, 1935 \\
\hline Bramatherium megacephalum & AM 19460 & 398 & 61 & 15,33 & Colbert, 1935 \\
\hline Sivatherium giganteum & OR 17102 & 320 & 57,53 & 17,98 & \\
\hline Sivatherium giganteum & OR 39605 & 320 & 66,85 & 20,89 & \\
\hline Sivatherium giganteum & OR 17102a & 312 & 59,69 & 19,13 & \\
\hline Sivatherium giganteum & OR 39600 & 327 & 72,83 & 22,27 & \\
\hline
\end{tabular}


RIOS, DANOWITZ, \& SOLOUNIA: THE METAPODIALS OF GIRAFFIDAE

TABLE 1 (continued).

\begin{tabular}{|c|c|c|c|c|c|}
\hline Species & Specimen $n^{\circ}$ & $\begin{array}{c}\text { Total } \\
\text { Length }\end{array}$ & Diaph. TD & RI & Reference \\
\hline Sivatherium giganteum & OR 39533 & 340 & 69,1 & 20,32 & \\
\hline Sivatherium giganteum & OR 11089 & 302 & 59,54 & 19,72 & \\
\hline Sivatherium giganteum & OR 17101 & 313 & 68,16 & 21,78 & \\
\hline Sivatherium giganteum & OR 39603 & 310 & 72,83 & 23,49 & \\
\hline Sivatherium giganteum & OR 17092 & & 69,07 & & \\
\hline Sivatherium giganteum & BM 39533 & 355 & & & Singer and Boné, 1960 \\
\hline Sivatherium giganteum & & 348 & & & Dietrich, 1942 \\
\hline Decennatherium pachecoi & MNCN-42769 & 391 & 36,17 & 9,25 & \\
\hline Decennatherium pachecoi & & & 44,5 & & Crusafont, 1952 \\
\hline Birgerbohlinia schaubi & IPS-935 & 373 & 48,89 & 13,11 & \\
\hline Birgerbohlinia schaubi & IPS-7640 & 382 & 48,3 & 12,64 & \\
\hline Birgerbohlinia schaubi & IPS-5060 & 374 & 47,28 & 12,64 & \\
\hline Birgerbohlinia schaubi & IPS-5059 & 381 & 51,01 & 13,39 & \\
\hline Birgerbohlinia schaubi & IPS-5061 & & 54,58 & & \\
\hline Birgerbohlinia schaubi & IPS-5010 & & 51,14 & & \\
\hline Birgerbohlinia schaubi & IPS-5014 & & 63,4 & & \\
\hline Birgerbohlinia schaubi & IPS-7629 & & 52,12 & & \\
\hline Birgerbohlinia schaubi & MGUV-7806 & 391 & 62,22 & 15,91 & \\
\hline Okapia johnstoni & AMNH 51218 & 320 & & & \\
\hline Okapia johnstoni & AMNH 51903 & 321 & 32,98 & 10,27 & \\
\hline Okapia johnstoni & AMNH 51903 & 322 & 33,96 & 10,55 & \\
\hline Okapia johnstoni & AMNH 51200 & 316 & 30,27 & 9,58 & \\
\hline Okapia johnstoni & AMNH 51196 & 305 & 32,02 & 10,50 & \\
\hline Okapia johnstoni & AMNH 51200 & 315 & 31,31 & 9,94 & \\
\hline Okapia johnstoni & AMNH 51197 & 330 & 34,11 & 10,34 & \\
\hline Okapia johnstoni & AMNH 2268 & 317 & 32,13 & 10,14 & \\
\hline Okapia johnstoni & AMNH 51196 & 306 & 31,97 & 10,45 & \\
\hline Okapia johnstoni & AMNH 51197 & 328 & 34,26 & 10,45 & \\
\hline Okapia johnstoni & AMNH 51198 & 312 & 32,05 & 10,27 & \\
\hline Okapia johnstoni & AMNH 2268 & 321 & 33,47 & 10,43 & \\
\hline Okapia johnstoni & AMNH 51198 & 313 & 31,73 & 10,14 & \\
\hline Okapia johnstoni & MNCN-11425 & 295,3 & 31,32 & 10,61 & \\
\hline Okapia johnstoni & MA (6) O (I) & 307,5 & 32,9 & 10,70 & Churcher, 1970 \\
\hline Samotherium major & AMNH 10742 & 390 & 48,64 & 12,47 & \\
\hline Samotherium major & AMNH 20758 & 395 & 54,18 & 13,72 & \\
\hline Samotherium major & AMNH 22969 & 399 & 56,69 & 14,21 & \\
\hline Samotherium major & AMNH 20758 & 399 & 53,48 & 13,40 & \\
\hline Samotherium major & AMNH 22845 & 405 & 56,53 & 13,96 & \\
\hline Samotherium major & AMNH 22843-A & 405 & 57,14 & 14,11 & \\
\hline
\end{tabular}


TABLE 1 (continued).

\begin{tabular}{|c|c|c|c|c|c|}
\hline Species & Specimen $n^{\circ}$ & $\begin{array}{c}\text { Total } \\
\text { Length }\end{array}$ & Diaph. TD & RI & Reference \\
\hline Samotherium major & AMNH 95122 & 409 & 51,22 & 12,52 & \\
\hline Samotherium major & AMNH 20595 & 412 & 54,11 & 13,13 & \\
\hline Samotherium major & AMNH 95121 & 415 & 52,73 & 12,71 & \\
\hline Samotherium major & AMNH 22973 & 416 & 54,58 & 13,12 & \\
\hline Samotherium major & AMNH 22970 & 416 & 53,33 & 12,82 & \\
\hline Samotherium major & AMNH 20614 & 423 & 49,71 & 11,75 & \\
\hline Samotherium major & AMNH 22971 & 428 & 57,82 & 13,51 & \\
\hline Samotherium major & AMNH 20636 & 471 & 52,48 & 11,14 & \\
\hline Samotherium major & MGL S32 & 415 & 47,6 & 11,47 & Kostopoulos, 2009 \\
\hline Samotherium major & PIM329 & 423 & 99 & 23,40 & Kostopoulos, 2009 \\
\hline Samotherium major & PMMS68 & 423 & 50,4 & 11,91 & Kostopoulos, 2009 \\
\hline Samotherium major & MYT41 & 397 & 52,4 & 13,20 & Kostopoulos, 2009 \\
\hline Samotherium major & AMNH20595 Q1 & 425 & 54,1 & 12,73 & Kostopoulos, 2009 \\
\hline Samotherium major & AMNH95121 Q1 & 415 & 53,4 & 12,87 & Kostopoulos, 2009 \\
\hline Samotherium major & MGL S35 & 423 & 50,3 & 11,89 & Kostopoulos, 2009 \\
\hline Samotherium major & PIM328 & 440 & 55 & 12,50 & Kostopoulos, 2009 \\
\hline Samotherium major & AMNH20614 Q1 & 432 & 49,3 & 11,41 & Kostopoulos, 2009 \\
\hline Samotherium major & MTLA76 & 425 & 58,7 & 13,81 & Kostopoulos, 2009 \\
\hline Samotherium major & AMNH95122 Q1 & 414 & 52 & 12,56 & Kostopoulos, 2009 \\
\hline Samotherium major & MTLA450 & 427 & 54,2 & 12,69 & Kostopoulos, 2009 \\
\hline Samotherium major & AMNH22973 Q5 & 420 & 41,9 & 9,98 & Kostopoulos, 2009 \\
\hline Samotherium major & PIM330 & 445 & 52 & 11,69 & Kostopoulos, 2009 \\
\hline Samotherium major & AMNH22971 Q5 & 440 & 57,2 & 13,00 & Kostopoulos, 2009 \\
\hline Samotherium major & PIM327 & 435 & 98 & 22,53 & Kostopoulos, 2009 \\
\hline Samotherium major & PIM336 & 413 & 51,7 & 12,52 & Kostopoulos, 2009 \\
\hline Samotherium major & PIM337 & 405 & 49,3 & 12,17 & Kostopoulos, 2009 \\
\hline Samotherium major & PIM324 & 427 & 47 & 11,01 & Kostopoulos, 2009 \\
\hline Samotherium major & AMNH22969 Q5 & 412 & 55,6 & 13,50 & Kostopoulos, 2009 \\
\hline Samotherium major & AMNH nn Q6 & 423 & 57,5 & 13,59 & Kostopoulos, 2009 \\
\hline Samotherium major & AMNH22970 Q5 & 420 & 43,2 & 10,29 & Kostopoulos, 2009 \\
\hline Samotherium major & PIM326 & 423 & 102 & 24,11 & Kostopoulos, 2009 \\
\hline Samotherium major & MTLA75 & 413 & 56,3 & 13,63 & Kostopoulos, 2009 \\
\hline Samotherium major & AMNH20758 Q4 & 400 & 53,5 & 13,38 & Kostopoulos, 2009 \\
\hline Samotherium major & MTLA117 & & 57,3 & & Kostopoulos, 2009 \\
\hline Samotherium major & MTLA398 & & 51 & & Kostopoulos, 2009 \\
\hline Samotherium major & MTLA399 & & 55,3 & & Kostopoulos, 2009 \\
\hline Samotherium major & MNHN SLQ690 & 410 & 40 & 9,76 & \\
\hline Samotherium major & MNHN SLQ691 & 408 & 41 & 10,05 & \\
\hline Samotherium major & KTA133 & 408 & 50 & 12,25 & Geraads, 1994 \\
\hline
\end{tabular}


RIOS, DANOWITZ, \& SolounIA: THE METAPOdIALS OF GIRAFFIDAE

TABLE 1 (continued).

\begin{tabular}{|c|c|c|c|c|c|}
\hline Species & Specimen $n^{\circ}$ & $\begin{array}{c}\text { Total } \\
\text { Length }\end{array}$ & Diaph. TD & RI & Reference \\
\hline Samotherium major & KTB61 & 421 & 55 & 13,06 & Geraads, 1994 \\
\hline Samotherium major & & 410 & & & Bohlin, 1926 \\
\hline Palaeotragus rouenii & M 11406 & 403 & 34,98 & 8,68 & \\
\hline Palaeotragus rouenii & M 11406 & & 34,35 & & \\
\hline Palaeotragus rouenii & MTLB155 & 434 & 38,3 & 8,82 & Kostopoulos, 2009 \\
\hline Palaeotragus rouenii & MGL S781 & 410 & 37,4 & 9,12 & Kostopoulos, 2009 \\
\hline Palaeotragus rouenii & KTD26 & 405 & 33,5 & 8,27 & Geraads, 1994 \\
\hline Palaeotragus rouenii & KTA7 & & 32,5 & & Geraads, 1994 \\
\hline Palaeotragus rouenii & KTD27 & & 32 & & Geraads, 1994 \\
\hline Palaeotragus rouenii & MNHN PIK1692 & 432 & 22 & 5,09 & \\
\hline Palaeotragus rouenii & AMPG 1040/91 & 428 & 26 & 6,07 & \\
\hline Palaeotragus rouenii & BM M 11406 & 398 & & & Bohlin, 1926 \\
\hline Palaeotragus rouenii & $11406 b$ & & 32,8 & & Churcher, 1970 \\
\hline Palaeotragus rouenii & $\mathrm{BM}$ a & 403 & 31,8 & 7,89 & Churcher, 1970 \\
\hline Bohlinia attica & AMNH 10453 & 710 & 48,87 & 6,88 & \\
\hline Bohlinia attica & M 11403 & 700 & 58,24 & 8,32 & \\
\hline Bohlinia attica & M 11401 & & 50,12 & & \\
\hline Bohlinia attica & MNHN PIK27561 & 715 & 48 & 6,71 & \\
\hline Bohlinia attica & & 710 & 47 & 6,62 & Geraads et al., 2005 \\
\hline Bohlinia attica & VTK 80 & 661 & 45 & 6,81 & Geraads, 1979 \\
\hline Bohlinia attica & VTK 79 & 693 & 50 & 7,22 & Geraads, 1979 \\
\hline Bohlinia attica & & 690 & & & Geraads, 1998 \\
\hline Bohlinia attica & & 730 & 57 & 7,81 & Geraads et al., 2005 \\
\hline Bohlinia attica & & 700 & 60 & 8,57 & Geraads et al., 2005 \\
\hline Bohlinia attica & & 695 & 60,5 & 8,71 & Geraads et al., 2005 \\
\hline Bohlinia attica & & & 50 & & Geraads et al., 2005 \\
\hline Bohlinia attica & AMPG 1923/91 & 655 & 47 & 7,18 & \\
\hline Bohlinia attica & AMPG 1925/91 & 720 & 40 & 5,56 & \\
\hline Giraffa camelopardalis & AMNH 70016 & 693 & 45,74 & 6,60 & \\
\hline Giraffa camelopardalis & AMNH 70016 & 695 & 47,04 & 6,77 & \\
\hline Giraffa camelopardalis & AMNH 14135 & 622 & 44,09 & 7,09 & \\
\hline Giraffa camelopardalis & AMNH 14135 & 621 & 45,31 & 7,30 & \\
\hline Giraffa camelopardalis & MNCN-3439 & 605 & 39,61 & 6,55 & \\
\hline Giraffa camelopardalis & AMNH 53543 & 650 & 47,32 & 7,28 & \\
\hline Giraffa camelopardalis & AMNH 53550 & 753 & 54,09 & 7,18 & \\
\hline Giraffa camelopardalis & AMNH 53550 & 745 & 52,15 & 7,00 & \\
\hline Giraffa camelopardalis & AMNH 82001 & 730 & 57 & 7,81 & \\
\hline Giraffa camelopardalis & KNM OM 2278 & 667 & & & Harris, 1976 \\
\hline Giraffa camelopardalis & KNM OM 2269 & 735 & & & Harris, 1976 \\
\hline
\end{tabular}


TABLE 1 (continued).

\begin{tabular}{|c|c|c|c|c|c|}
\hline Species & Specimen $n^{\circ}$ & $\begin{array}{c}\text { Total } \\
\text { Length }\end{array}$ & Diaph. TD & $\mathbf{R I}$ & Reference \\
\hline Giraffa camelopardalis & KNM OM 2272 & 624 & & & Harris, 1976 \\
\hline Giraffa camelopardalis & KNM OM 2217 & 738 & & & Harris, 1976 \\
\hline
\end{tabular}

lished the following categories (Figure 2; Tables 4, 6):

1. Long: $>510 \mathrm{~mm}$, Bohlinia attica and Giraffa camelopardalis,

2. Medium: between 510 and $350 \mathrm{~mm}$, most species fall into this category. Birgerbohlinia schaubi, Sivatherium giganteum, Decennatherium pachecoi, and Palaeotragus rouenii fall into the medium-short range, with most specimens between 350 and $450 \mathrm{~mm}$, while Bramatherium megacephalum, Helladotherium duvernoyi, and Samotherium major fall into the medium-long category, with most specimens over $450 \mathrm{~mm}$.

3. Short: $<350 \mathrm{~mm}$, Canthumeryx sirtensis and Okapia johnstoni fall in this category.

Using descriptive parameters above, we also plot the total length versus the midshaft minimum transverse diameter of the metatarsals, to demonstrate the relative slenderness of the limbs.

\section{DISCUSSION}

Ruminant limbs exhibit morphometric and anatomical features that are often used in phyloge- netic analyses to classify and unite higher order groups (Heinz, 1963; Janis and Scott, 1987; Janis and Theodor, 2014; Silvia et al., 2014).The artiodactyl astragalus, for example, is modified to possess two trochleae, allowing for pronounced dorsoplantar motion and limited mediolateral motion with the double-pullied structure (Thewissen and Madar, 1999). Ruminantia are united by the fusion of the cuboid and navicular, and fusion of the magnum and trapezoid (Janis and Theodor, 2014). Cervid metatarsals can be categorized by a closed metatarsal gully distally on the dorsal surface, whereas in bovids and giraffids, the gully is continuous throughout the shaft (Leinders, 1979; Janis and Theodor, 2014). Limb dimensions give valuable insight into the body size of the individual (Scott, 1985), however, it is the detailed morphological features that allow for the separation of families, or even species.

The modern giraffe is a unique and remarkable ruminant, with extreme metapodial elongation, and metatarsal lengths exceeding those of the tibia (Janis et al., 2002). Extant giraffids are unique from cervids and bovids in that the lateral metatarsal splint bones are rarely present, while the medial metatarsal splint bones are relatively common (Sil-

TABLE 2. Descriptive parameters of the metacarpal robustness index of the Giraffidae (Max., maximum; Min., minimum; SD, standard deviation; Ntotal, total sample size).

\begin{tabular}{lccccc}
\hline & \multicolumn{3}{c}{$\mathbf{R}$} \\
\cline { 2 - 6 } & Max. & Mean & Min. & SD & N total \\
\hline Birgerbohlinia schaubi & 15.91 & 13.54 & 12.64 & 1.36 & 5 \\
Bohlinia attica & 8.71 & 7.31 & 5.56 & 0.96 & 11 \\
Bramatherium megacephalum & 15.33 & 13.96 & 13.11 & 1.20 & 3 \\
Canthumeryx sirtensis & 6.03 & 6.03 & 6.03 & & 1 \\
Decennatherium pachecoi & 9.25 & 9.25 & 9.25 & & 1 \\
Giraffa camelopardalis & 7.81 & 7.06 & 6.55 & 0.39 & 9 \\
Helladotherium duvernoyi & 16.79 & 14.51 & 11.65 & 1.65 & 12 \\
Okapia johnstoni & 10.70 & 10.31 & 9.58 & .29 & 14 \\
Palaeotragus rouenii & 9.12 & 7.71 & 5.09 & 1.53 & 7 \\
Samotherium major & 24.11 & 13.24 & 9.76 & 3.02 & 43 \\
Sivatherium giganteum & 23.49 & 20.70 & 17.98 & 1.79 & 8 \\
\hline
\end{tabular}


RIOS, DANOWITZ, \& SOLOUNIA: THE METAPODIALS OF GIRAFFIDAE

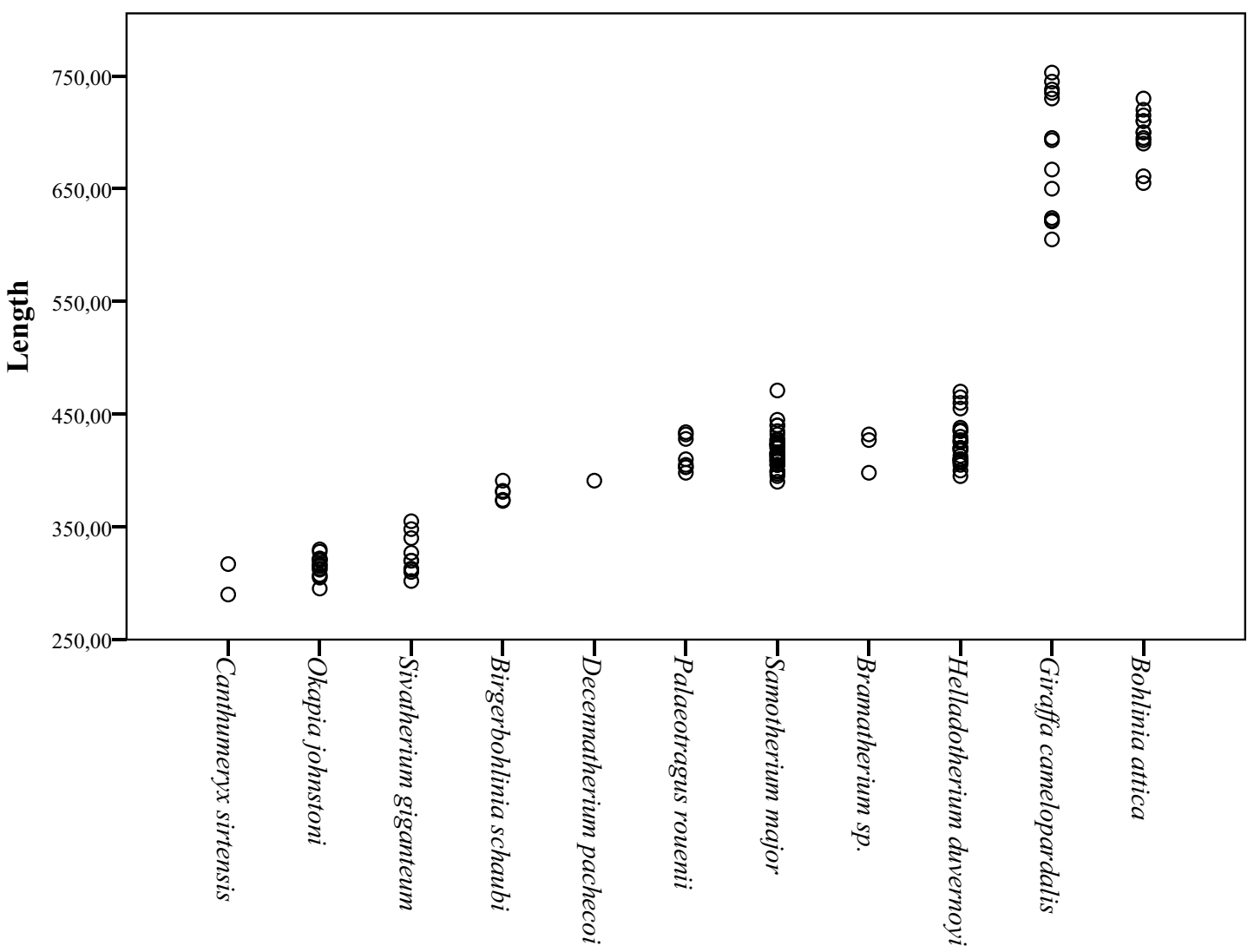

FIGURE 20. Dispersion plot with the absolute metacarpal length of the Giraffidae analyzed.

TABLE 3. Descriptive parameters of the metacarpal length of the Giraffidae (Max., maximum; Min., minimum; SD, standard deviation; Ntotal, total sample size).

\begin{tabular}{|c|c|c|c|c|c|}
\hline & \multicolumn{5}{|c|}{ Length } \\
\hline & Mean & Max. & Min. & SD & $\mathrm{N}$ total \\
\hline Canthumeryx sirtensis & 303.50 & 317.00 & 290.00 & 19.09 & 2 \\
\hline Helladotherium duvernoyi & 424.79 & 470.00 & 395.00 & 19.56 & 29 \\
\hline Bramatherium megacephalum & 419.00 & 432.00 & 398.00 & 18.36 & 3 \\
\hline Sivatherium giganteum & 324.70 & 355.00 & 302.00 & 17.56 & 10 \\
\hline Decennatherium pachecoi & 391.00 & 391.00 & 391.00 & & 1 \\
\hline Birgerbohlinia schaubi & 380.20 & 391.00 & 373.00 & 7.26 & 5 \\
\hline Okapia johnstoni & 315.25 & 330.00 & 295.30 & 9.19 & 15 \\
\hline Samotherium major & 417.61 & 471.00 & 390.00 & 14.79 & 44 \\
\hline Palaeotragus rouenii & 414.13 & 434.00 & 398.00 & 14.71 & 8 \\
\hline Bohlinia attica & 698.25 & 730.00 & 655.00 & 22.17 & 12 \\
\hline Giraffa camelopardalis & 682.92 & 753.00 & 605.00 & 54.31 & 13 \\
\hline
\end{tabular}




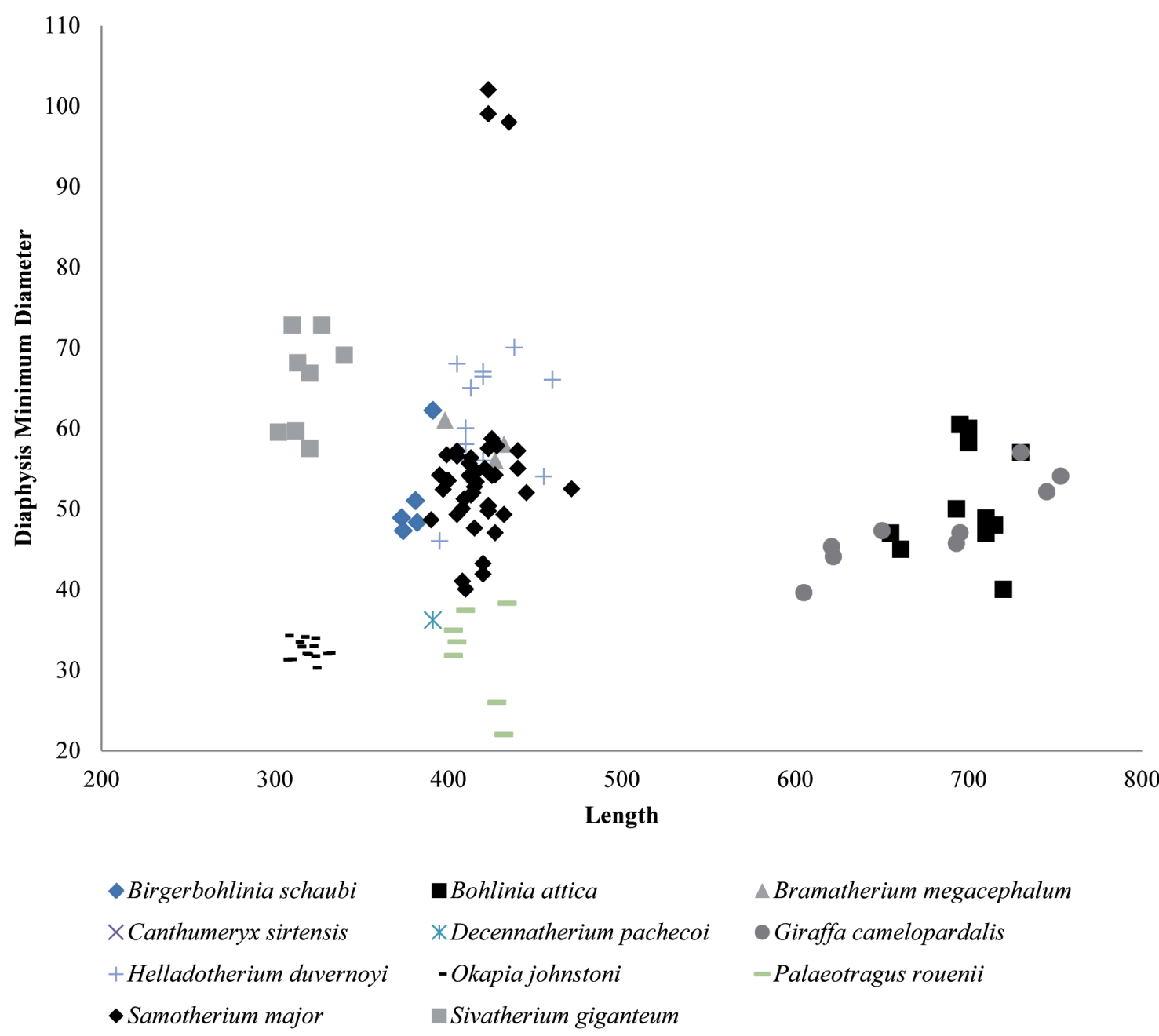

FIGURE 21. Dispersion plot showing the total length of the metacarpals versus the midshaft minimum transverse diameter of the Giraffidae analyzed.

via et al., 2014). The articular morphologies of giraffid metatarsals are unique among Pecora as well, whereas few differences have been noted among cervids, bovids, moschids, and antilocaprids (Janis and Theodor, 2014). Solounias (2007) demonstrated that the subfamilies of Giraffidae could be separated based on metapodial anatomical features and proportions. Using a more detailed anatomical analysis on the giraffid metapodials, we now find inter-generic morphological differences within Giraffidae.

We find several morphological characteristics on the metacarpals that differ between giraffid genera. All giraffids included in the study exhibit a central groove at the proximo-palmar metacarpal surface that separates the medial and lateral epicondyles. The depth and length of this groove, however, is variable. In the sivatheres Helladothe- rium, Bramatherium, and Sivatherium, the groove is medium to shallow (Figure 5). Both extant giraffids, as well as Palaeotragus exhibit a shallow groove that is elongated. The presence of the pyramidal rise is also variable. We define the pyramidal rise as an elevated bony ridge located on the palmar surface of the central trough, which likely corresponds to an internal bony septum that is seen upon cross section. The pyramidal rise is faint on the Palaeotragus and giraffe metacarpals, distinct on the okapi, Samotherium, and Helladotherium metacarpals, and absent in all other giraffids.

The morphological descriptions reveal a unique metacarpal characteristic seen only in the sivatheres Bramatherium and Sivatherium. In these taxa, the proximal end of the metacarpal splays outward, so that the medial and lateral epicondyles are distinct and oriented away from each 


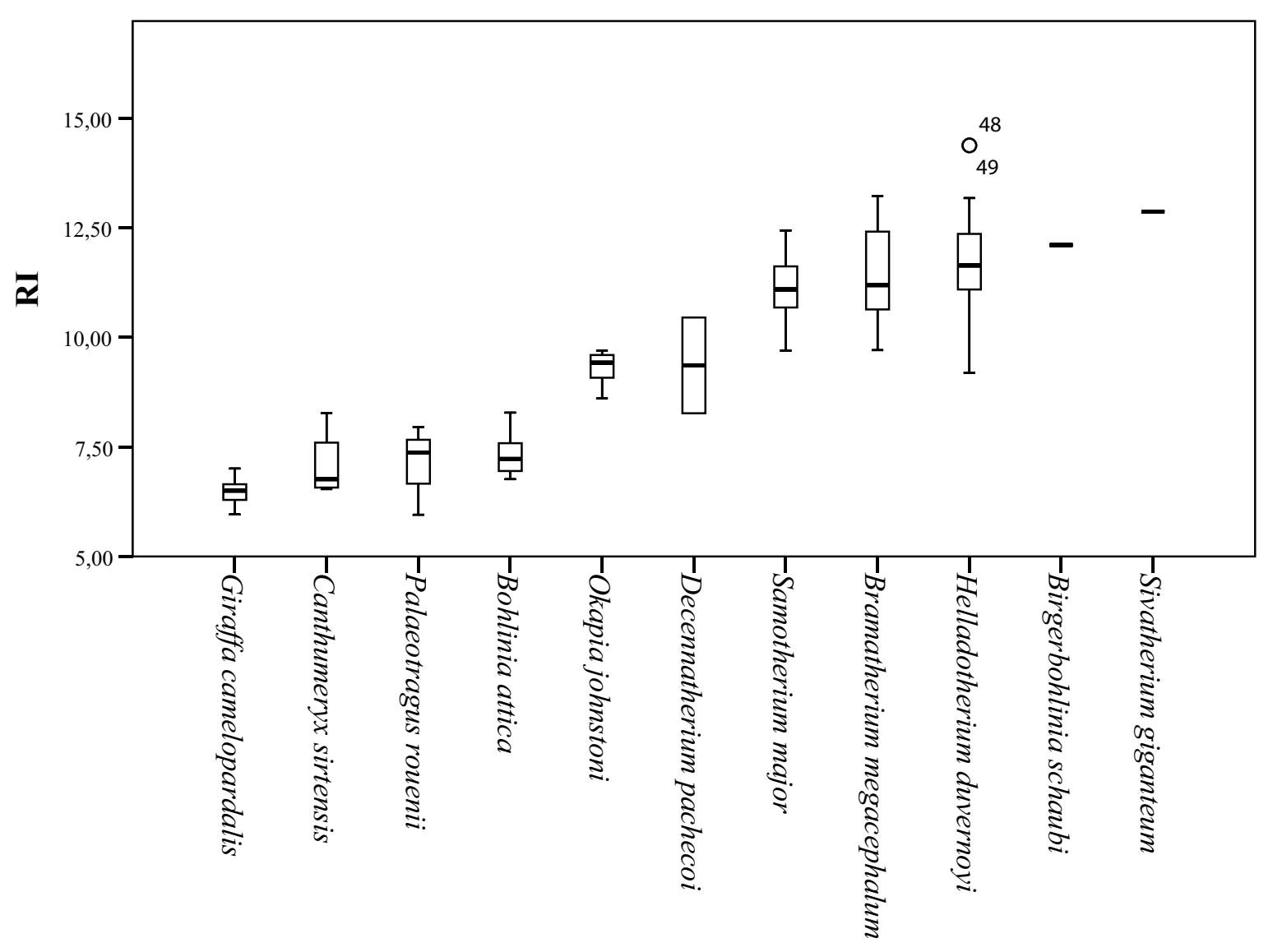

FIGURE 22. Box-and-whiskers plot with the metatarsal RI of the Giraffidae analyzed.

other (Figure 5). This slightly resembles the condition seen in camelids, where the third and fourth metatarsals splay distally (Janis et al., 2002); however, this feature is present on the proximal end of the metapodial and is less extreme. We believe this proximal splaying increases the surface area of the wrist joint and therefore, balances distribution of weight on the limb. Bramatherium and Sivatherium are both from the same region; therefore, this shared metacarpal morphology may represent an environmental signal, reflecting the topography of the Upper Siwaliks. Helladotherium exhibits a very slight outward splaying of the proximal metacarpals, and this character may also reflect phylogenetic similarities between the sivatheres.

The proximo-palmar morphology of the metacarpal reveals several similarities between Helladotherium, Palaeotragus, and Bohlinia, the giraffids from Pikermi. These taxa exhibit a depression on the medial epicondyle, just distal to the articular surface. The Pikermian giraffids also share a triangular expansion of the articular surface onto the lateral epicondyle. These features are most pro- nounced in Bohlinia and are absent in all other giraffids. The medial depression and lateral expansion of the articular surface likely corresponds to increased bending at the wrist. As Helladotherium, Palaeotragus, and Bohlinia all belong to separate subfamilies, we believe these anatomical similarities reflect an environmental rather than a phylogenetic signal.

The central trough was first categorized in Solounias (2007) as a useful feature to separate taxa based on the varying depths. This study demonstrated that the trough can be characterized into three depths (shallow, intermediate, and deep), and therefore facilitate giraffid limb identifications (Figures 7,17 ). The central trough is created by the elevated medial and lateral ridges on the metapodials. In all taxa, the central trough becomes subdued or completely flattened by the distal shaft. With the exception of the shortened metapodials of Canthumeryx, Sivatherium (only the metacarpal), and the okapi, and the elongated metapodials of Bohlinia and the giraffe, all giraffids fall within a common intermediate range for length 
TABLE 4. Dimensions in $\mathrm{mm}$ of the metatarsal III-IV of Giraffidae (DT, transversal diameter; Diaph., diaphysis; RI, robustness index).

\begin{tabular}{|c|c|c|c|c|c|}
\hline Species & Specimen $n^{\circ}$ & $\begin{array}{c}\text { Total } \\
\text { Length }\end{array}$ & Diaph. TD & RI & Reference \\
\hline Canthumeryx sirtensis & KNH MO 41 & 278 & 23 & 8.27 & \\
\hline Canthumeryx sirtensis & KNM .M0.41B & 280 & 18.5 & 6.61 & Hamilton, 1978 \\
\hline Canthumeryx sirtensis & IPP 1933-9 & 260 & 18 & 6.92 & Hamilton, 1978 \\
\hline Canthumeryx sirtensis & BU 20117 & 349 & & & Hamilton, 1978 \\
\hline Canthumeryx sirtensis & UCB. V. 4899/42058 & 260 & 17 & 6.54 & Hamilton, 1978 \\
\hline Helladotherium duvernoyi & MNHN PIK1564 & 450 & 48 & 10.67 & \\
\hline Helladotherium duvernoyi & MNHN PIK1563 & 440 & 55 & 12.50 & \\
\hline Helladotherium duvernoyi & MNHN PIK1565 & 435 & 40 & 9.20 & \\
\hline Helladotherium duvernoyi & MNHN PIK1554 & 440 & 58 & 13.18 & \\
\hline Helladotherium duvernoyi & M 11382 & 436 & 49.36 & 11.32 & \\
\hline Helladotherium duvernoyi & M 11384 & 441 & 50.47 & 11.44 & \\
\hline Helladotherium duvernoyi & M 8364 & 434 & 49.38 & 11.38 & \\
\hline Helladotherium duvernoyi & M 11384 & 450 & 53.29 & 11.84 & \\
\hline Helladotherium duvernoyi & M 11383 & 456 & 50.59 & 11.09 & \\
\hline Helladotherium duvernoyi & M 11383 & 456 & 50.59 & 11.09 & \\
\hline Helladotherium duvernoyi & M 11381 & 435 & 62.57 & 14.38 & \\
\hline Helladotherium duvernoyi & M 11381 & 435 & 62.57 & 14.38 & \\
\hline Helladotherium duvernoyi & $1972 / 10$ & 458 & 56 & 12.23 & Melentis, 1974 \\
\hline Helladotherium duvernoyi & MNHN PIK1566 & 455 & 55 & 12.09 & \\
\hline Helladotherium duvernoyi & AMNH 27805 & 495 & 60 & 12.12 & \\
\hline Helladotherium duvernoyi & MTLA85 & 480 & 52 & 10.83 & Kostopoulos, 2009 \\
\hline Helladotherium duvernoyi & BM M 11382 & 440 & & & Bohlin, 1926 \\
\hline Helladotherium duvernoyi & RMS & 465 & & & Bohlin, 1926 \\
\hline Helladotherium duvernoyi & & 440 & & & Pilgrim, 1911 \\
\hline Helladotherium duvernoyi & BM M 11381 & 440 & & & Bohlin, 1926 \\
\hline Bramatherium megacephalum & AMNH 19770 & 452 & 50.6 & 11.19 & \\
\hline Bramatherium megacephalum & AMNH 19464 & 382 & 40.64 & 10.64 & \\
\hline Bramatherium megacephalum & AMNH 19831 & 442 & 42.92 & 9.71 & \\
\hline Bramatherium megacephalum & AMNH 19688 & 421 & 52.27 & 12.42 & \\
\hline Bramatherium megacephalum & & 465 & 61.5 & 13.23 & Geraads \& Güleç, 1999 \\
\hline Sivatherium giganteum & OR 39752 & 410 & 52.77 & 12.87 & \\
\hline Sivatherium giganteum & OR 39752 & 410 & 52.77 & 12.87 & \\
\hline Sivatherium giganteum & OR 17089 & & 56.2 & & \\
\hline Sivatherium giganteum & OR 17090 & & 59.84 & & \\
\hline Sivatherium giganteum & OR 39753 & & 58.73 & & \\
\hline Sivatherium giganteum & OR 17090 & & 59.84 & & \\
\hline Sivatherium giganteum & OR 39753 & & 58.73 & & \\
\hline Sivatherium giganteum & OR 17089 & & 56.2 & & \\
\hline Sivatherium giganteum & & 415 & & & Bohlin, 1926 \\
\hline Decennatherium pachecoi & MNCN-42764 & 427.5 & 35.35 & 8.27 & \\
\hline Decennatherium pachecoi & MNCN-42765 & 406.14 & 42.46 & 10.45 & \\
\hline Decennatherium pachecoi & MNCN-42771 & & 38.4 & & \\
\hline Decennatherium pachecoi & MNCN-42778 & & 34.94 & & \\
\hline
\end{tabular}


RIOS, DANOWITZ, \& SOLOUNIA: THE METAPODIALS OF GIRAFFIDAE

TABLE 4 (continued).

\begin{tabular}{|c|c|c|c|c|c|}
\hline Species & Specimen $n^{0}$ & $\begin{array}{c}\text { Total } \\
\text { Length }\end{array}$ & Diaph. TD & RI & Reference \\
\hline Decennatherium pachecoi & MNCN-42770 & & 36.17 & & \\
\hline Decennatherium pachecoi & MNCN-42766 & & 36.59 & & \\
\hline Decennatherium pachecoi & MNCN-42767 & & 35.88 & & \\
\hline Decennatherium pachecoi & MNCN-42768 & & 33.38 & & \\
\hline Decennatherium pachecoi & & & 40 & & Crusafont, 1952 \\
\hline Birgerbohlinia schaubi & IPS-5015 & & 48.51 & & \\
\hline Birgerbohlinia schaubi & IPS-4981 & & 47.48 & & \\
\hline Birgerbohlinia schaubi & $N^{\circ} 48$ & 410 & & & Crusafont, 1952 \\
\hline Birgerbohlinia schaubi & No183 & 384 & 46.5 & 12.11 & Crusafont, 1952 \\
\hline Birgerbohlinia schaubi & IPS-5090 & & 48.08 & & \\
\hline Okapia johnstoni & AMNH 51218 & 330 & 32 & 9.70 & \\
\hline Okapia johnstoni & AMNH 51903 & 325 & 30.6 & 9.42 & \\
\hline Okapia johnstoni & AMNH 51903 & 324 & 29.98 & 9.25 & \\
\hline Okapia johnstoni & AMNH 51198 & 327 & 29.62 & 9.06 & \\
\hline Okapia johnstoni & AMNH 51200 & 322 & 27.73 & 8.61 & \\
\hline Okapia johnstoni & AMNH 51196 & 319 & 30.62 & 9.60 & \\
\hline Okapia johnstoni & AMNH 51196 & 318 & 30.63 & 9.63 & \\
\hline Okapia johnstoni & AMNH 51200 & 321 & 28.15 & 8.77 & \\
\hline Okapia johnstoni & AMNH 2268 & 332 & 31.89 & 9.61 & \\
\hline Okapia johnstoni & AMNH 51197 & 335 & 31.6 & 9.43 & \\
\hline Okapia johnstoni & AMNH 51197 & 334 & 31.6 & 9.46 & \\
\hline Okapia johnstoni & AMNH 51198 & 326 & 29.6 & 9.08 & \\
\hline Okapia johnstoni & MNCN-11425 & 317 & 30.34 & 9.57 & \\
\hline Okapia johnstoni & $\mathrm{MA}(6) \mathrm{O}(\mathrm{I})$ & 316.2 & 29.3 & 9.27 & Churcher, 1970 \\
\hline Samotherium major & PIM350 & 465 & 50 & 10.75 & Kostopoulos, 2009 \\
\hline Samotherium major & PIM344 & 460 & 49 & 10.65 & Kostopoulos, 2009 \\
\hline Samotherium major & MGL S95 & 473 & 48.7 & 10.30 & Kostopoulos, 2009 \\
\hline Samotherium major & AMNH20636 Q1 & 495 & 48 & 9.70 & Kostopoulos, 2009 \\
\hline Samotherium major & MGL S94 & 465 & 51 & 10.97 & Kostopoulos, 2009 \\
\hline Samotherium major & AMNH28845B Q4 & 480 & 55.1 & 11.48 & Kostopoulos, 2009 \\
\hline Samotherium major & PIM360 & 470 & 48 & 10.21 & Kostopoulos, 2009 \\
\hline Samotherium major & AMNH20615 Q1 & 447 & 49.7 & 11.12 & Kostopoulos, 2009 \\
\hline Samotherium major & AMNH20633 Q1 & 500 & 56.4 & 11.28 & Kostopoulos, 2009 \\
\hline Samotherium major & PIM359 & 460 & & & Kostopoulos, 2009 \\
\hline Samotherium major & AMNH22697 Q5 & 465 & 56.2 & 12.09 & Kostopoulos, 2009 \\
\hline Samotherium major & AMNH28845A Q4 & 470 & 53.1 & 11.30 & Kostopoulos, 2009 \\
\hline Samotherium major & AMNH20595 Q1 & 465 & 53.5 & 11.51 & Kostopoulos, 2009 \\
\hline Samotherium major & MTLA279 & 503 & 55 & 10.93 & Kostopoulos, 2009 \\
\hline Samotherium major & MTLB401 & 475 & 50 & 10.53 & Kostopoulos, 2009 \\
\hline Samotherium major & MTLA387 & 463 & 57.6 & 12.44 & Kostopoulos, 2009 \\
\hline Samotherium major & MTLA247 & 495 & 59.3 & 11.98 & Kostopoulos, 2009 \\
\hline Samotherium major & PIM346 & 475 & 57.7 & 12.15 & Kostopoulos, 2009 \\
\hline Samotherium major & MTLA72 & 480 & 47.4 & 9.88 & Kostopoulos, 2009 \\
\hline
\end{tabular}


TABLE 4 (continued).

\begin{tabular}{|c|c|c|c|c|c|}
\hline Species & Specimen $n^{\circ}$ & $\begin{array}{c}\text { Total } \\
\text { Length }\end{array}$ & Diaph. TD & $\mathbf{R I}$ & Reference \\
\hline Samotherium major & SLQ690 & 460 & & & Kostopoulos, 2009 \\
\hline Samotherium major & PIM48 & 460 & 54 & 11.74 & Kostopoulos, 2009 \\
\hline Samotherium major & MTLA470 & 475 & 52.1 & 10.97 & Kostopoulos, 2009 \\
\hline Samotherium major & AMNH22966 Q5 & 450 & 54.6 & 12.13 & Kostopoulos, 2009 \\
\hline Samotherium major & PIM352 & 430 & & & Kostopoulos, 2009 \\
\hline Samotherium major & PIM355 & 447 & 49.5 & 11.07 & Kostopoulos, 2009 \\
\hline Samotherium major & MTLA342 & & 56.4 & & Kostopoulos, 2009 \\
\hline Samotherium major & MGL S382b & & 47 & & Kostopoulos, 2009 \\
\hline Samotherium major & MGL S1063 & & 52 & & Kostopoulos, 2009 \\
\hline Samotherium major & MAR571 & 420 & 45 & 10.71 & \\
\hline Samotherium major & KTA134 & 462 & 53 & 11.47 & Geraads, 1994 \\
\hline Palaeotragus rouenii & PIK1691 & 420 & 25 & 5.95 & \\
\hline Palaeotragus rouenii & & 445 & 32.8 & 7.37 & Kostopoulos, 2009 \\
\hline Palaeotragus rouenii & & & 32.5 & & Kostopoulos, 2009 \\
\hline Palaeotragus rouenii & & & 30 & & Kostopoulos, 2009 \\
\hline Palaeotragus rouenii & & 377 & 30 & 7.96 & Geraads, 1994 \\
\hline Bohlinia attica & MNHN PIK2357 & 714 & 50 & 7.00 & \\
\hline Bohlinia attica & M 11403 & & 52.97 & & \\
\hline Bohlinia attica & M $11403(6)$ & & 49.36 & & \\
\hline Bohlinia attica & M 11403 & & 49.4 & & \\
\hline Bohlinia attica & M 11403 & & 48.33 & & \\
\hline Bohlinia attica & & 690 & & & Geraads et al., 2005 \\
\hline Bohlinia attica & MNHN SLQ682 & 709 & 48 & 6.77 & \\
\hline Bohlinia attica & & 680 & 46 & 6.76 & Geraads et al., 2005 \\
\hline Bohlinia attica & NKT-24 & 670 & 55.5 & 8.28 & Kostopoulos et al., 1996 \\
\hline Bohlinia attica & NKT-171 & 680 & 51.8 & 7.62 & Kostopoulos et al., 1996 \\
\hline Bohlinia attica & AUT & 658 & 49 & 7.45 & Geraads et al., 2005 \\
\hline Bohlinia attica & & 695 & 52.5 & 7.55 & Geraads et al., 2005 \\
\hline Bohlinia attica & FM2025 & & 56 & & Geraads et al., 2005 \\
\hline Bohlinia attica & MNHN MAR3254 & 692 & 50 & 7.23 & \\
\hline Bohlinia attica & & 620 & & & Mecquenem, 1924 \\
\hline Bohlinia attica & & 675 & 52 & 7.70 & Geraads et al., 2005 \\
\hline Bohlinia attica & AMNH 10453 & 702 & 48.43 & 6.90 & \\
\hline Bohlinia attica & AMPG 1972/63 & 680 & 49 & 7.21 & \\
\hline Giraffa camelopardalis & AMNH 82001 & 742 & 52 & 7.01 & \\
\hline Giraffa camelopardalis & AMNH 53543 & 658 & 45 & 6.84 & \\
\hline Giraffa camelopardalis & MNCN-3439 & 638 & 39.24 & 6.15 & \\
\hline Giraffa camelopardalis & AMNH 14135 & 625 & 39.32 & 6.29 & \\
\hline Giraffa camelopardalis & AMNH 53550 & 765 & 50.86 & 6.65 & \\
\hline Giraffa camelopardalis & AMNH 14135 & 626 & 40.02 & 6.39 & \\
\hline Giraffa camelopardalis & AMNH 53550 & 764 & 49.52 & 6.48 & \\
\hline Giraffa camelopardalis & AMNH 70016 & 685 & 45.43 & 6.63 & \\
\hline Giraffa camelopardalis & AMNH 70016 & 686 & 44.75 & 6.52 & \\
\hline
\end{tabular}


TABLE 4 (continued).

\begin{tabular}{|c|c|c|c|c|c|}
\hline Species & Specimen $n^{\circ}$ & $\begin{array}{c}\text { Total } \\
\text { Length }\end{array}$ & Diaph. TD & RI & Reference \\
\hline Giraffa camelopardalis & OM 2278 & 673 & & & Harris, 1976 \\
\hline Giraffa camelopardalis & & 660 & & & Harris, 1976 \\
\hline Giraffa camelopardalis & OM 2272 & 632 & & & Harris, 1976 \\
\hline Giraffa camelopardalis & OM 2217 & 732 & & & Harris, 1976 \\
\hline Giraffa camelopardalis & & 755 & & & Harris, 1976 \\
\hline Giraffa camelopardalis & OM 2269 & 748 & & & Harris, 1976 \\
\hline Giraffa camelopardalis & & 755 & 45 & 5.96 & Harris, 1976 \\
\hline
\end{tabular}

(Figures 20, 23). Therefore, additional features are needed to separate and define the giraffids. In the taxa with short metapodials, Canthumeryx exhibits a shallow trough, whereas the trough of Sivatherium and the okapi is intermediate in depth. The depth of the trough separates the elongate-metapodial giraffids as well; the central trough of Bohlinia is notably deep, whereas it is shallow in the giraffe. The central trough is a useful character that provides better separation between taxa than absolute metapodial length.

Heinz (1963) described proximal metatarsal morphologies that can be used to distinguish between cervids and bovids. Bovids exhibit a facet on the proximal plantar surface termed the diarthrodial facet, whereas cervids possess a bony protrusion in this position termed the posterior tuberosity. The term diarthrodial refers to a distinct facet adjacent to the main facet. Janis and Scott (1987) utilized the presence of the posterior tuber- osity to unite cervids and palaeomerycids. The pygmaios of giraffids described in the present study presents as relatively distinct from the proximal shaft and is positioned more centrally at the proximal plantar metatarsal surface. The morphology, size, and presence of the pygmaios are variable among the different giraffid species (Figure 16). While it is possible that the pygmaios is homologous to the posterior tuberosity described in cervids, we believe this is a separate structure that should not be used to unite the two groups. The giraffid pygmaios may also be homologous to the metatarsal sesamoid bone, which is variable among artiodactyls.

The presence and morphology of the giraffid pygmaios is another character that can be used to separate the metatarsals. Within the sivatheres, this structure is absent in Helladotherium, Sivatherium, and Birgerbohlinia, and is reduced and protrudes less proximally than the other giraffids in

TABLE 5. Descriptive parameters of the metatarsal robustness index of the Giraffidae (Max., maximum; Min., minimum; SD, standard deviation; Ntotal, total sample size).

\begin{tabular}{|c|c|c|c|c|c|}
\hline & \multicolumn{5}{|c|}{$\mathbf{R I}$} \\
\hline & Max. & Mean & Mín. & SD & $\mathrm{N}$ total \\
\hline Birgerbohlinia schaubi & 12.11 & 12.11 & 12.11 & & 1 \\
\hline Bohlinia attica & 8.28 & 7.32 & 6.76 & .46 & 11 \\
\hline Bramatherium megacephalum & 13.23 & 11.44 & 9.71 & 1.40 & 5 \\
\hline Canthumeryx sirtensis & 8.27 & 7.09 & 6.54 & .81 & 4 \\
\hline Decennatherium pachecoi & 10.45 & 9.36 & 8.27 & 1.55 & 2 \\
\hline Giraffa camelopardalis & 7.01 & 6.49 & 5.96 & .31 & 10 \\
\hline Helladotherium duvernoyi & 14.38 & 11.86 & 9.20 & 1.33 & 16 \\
\hline Okapia johnstoni & 9.70 & 9.32 & 8.61 & .33 & 14 \\
\hline Palaeotragus rouenii & 7.96 & 7.09 & 5.95 & 1.03 & 3 \\
\hline Samotherium major & 12.44 & 11.14 & 9.70 & .73 & 24 \\
\hline Sivatherium giganteum & 12.87 & 12.87 & 12.87 & 0.00 & 1 \\
\hline
\end{tabular}


TABLE 6. Descriptive parameters of the metatarsal length of the Giraffidae (Max., maximum; Min., minimum; SD, standard deviation; Ntotal, total sample size).

\begin{tabular}{|c|c|c|c|c|c|}
\hline & \multicolumn{5}{|c|}{ Length } \\
\hline & Mean & Max. & Min. & SD & $\mathrm{N}$ total \\
\hline Canthumeryx sirtensis & 285.4 & 349 & 260 & 36.81 & 5 \\
\hline Helladotherium duvernoyi & 449.05 & 495 & 434 & 16.22 & 20 \\
\hline Bramatherium megacephalum & 432.4 & 465 & 382 & 32.44 & 5 \\
\hline Sivatherium giganteum & 411.67 & 415 & 410 & 2.89 & 3 \\
\hline Decennatherium pachecoi & 416.82 & 427.5 & 406.14 & 15.1 & 2 \\
\hline Birgerbohlinia schaubi & 397 & 410 & 384 & 18.38 & 2 \\
\hline Okapia johnstoni & 324.73 & 335 & 316.2 & 6.27 & 14 \\
\hline Samotherium major & 467.04 & 503 & 420 & 19.07 & 27 \\
\hline Palaeotragus rouenii & 414 & 445 & 377 & 34.39 & 3 \\
\hline Bohlinia attica & 681.92 & 714 & 620 & 24.34 & 13 \\
\hline Giraffa camelopardalis & 696.5 & 765 & 625 & 53.76 & 16 \\
\hline
\end{tabular}

Bramatherium. In certain giraffids, the pygmaios is notably distinct from the medial and lateral epicondyles by deep medial and lateral grooves, as is seen in Deccenatherium, Samotherium, and Bohlinia. When present, it is rounded in all giraffids, with the exception of the primitive Canthumeryx, where it is pointed, and in the okapi and Bohlinia, where the proximal end is flattened. In the palaeotragines Samotherium and Palaeotragus, as well as in Birgerbohlinia, the pygmaios is oriented medially, and Canthumeryx is unique in that this structure is directed centrally. In the giraffe, the pygmaios is absent; however, there is a large depression with lipped edges in its position. When combined with the other metatarsal features, the presence, orientation, and distinctness of the pygmaios are useful features to separate giraffid genera.

The giraffid metatarsal is characterized by medial and lateral epicondyles, which are each separated into dorsal and plantar heads. The heads of the medial and lateral epicondyles are distinct in all giraffids; however, the grooves creating the separation are narrower and fainter in the giraffe. Another character uniting Giraffidae is the orientation of the medial and lateral epicondyles; the dorsal heads of all giraffid medial and lateral epicondyles flare outward, and the plantar heads are relatively straight. In Samotherium and Palaeotragus, the outward flaring of the dorsal head is more pronounced on the medial epicondyle. The Canthumeryx metatarsal represents the most extreme outward flare. While there are subtle differences between the individual species, the distinctness and general orientation of the heads of the medial and lateral epicondyles are features that are shared in the metatarsals of all giraffids.

The metatarsal proximal morphology (Figure 18) can also be used to separate between giraffids. While in Helladotherium duvernoyi, Bramatherium megacephalum, Birgerbohlinia schaubi, and Okapia johnstoni the os cuneiforme intermediolaterale and os cuneiforme mediale facets are separated, in Decennatherium pachecoi, Samotherium major, and Sivatherium giganteum both facets are in contact in a small point, and in Giraffa camelopardalis they can be contacting or slightly separated.

Morphological features of the giraffid metapodials are key characters that can be used in future genus and species identifications. Figures 4, 7, 1617 demonstrate that no two genera share the same combination of metapodial characters; each genus can be characterized by a unique combination of metapodial morphological features. Unlike dimensional features that show general metapodial patterns (Solounias, 2007), detailed morphological features allow for genus level identifications. Using these descriptions and simplified character tables, a giraffid metapodial specimen can be identified as either a genus included in this study, or as a new taxon. Our morphological characters can also be applied to bovids, cervids, and camelids to enrich the systematic investigations of known and unknown species.

Giraffid metapodials range largely in both length and robustness (Tables 1-6) providing with the possibility of establishing certain categories that can serve as a tool for future phylogenetic inferences. In the past, other authors have used these features of the appendicular skeleton to 


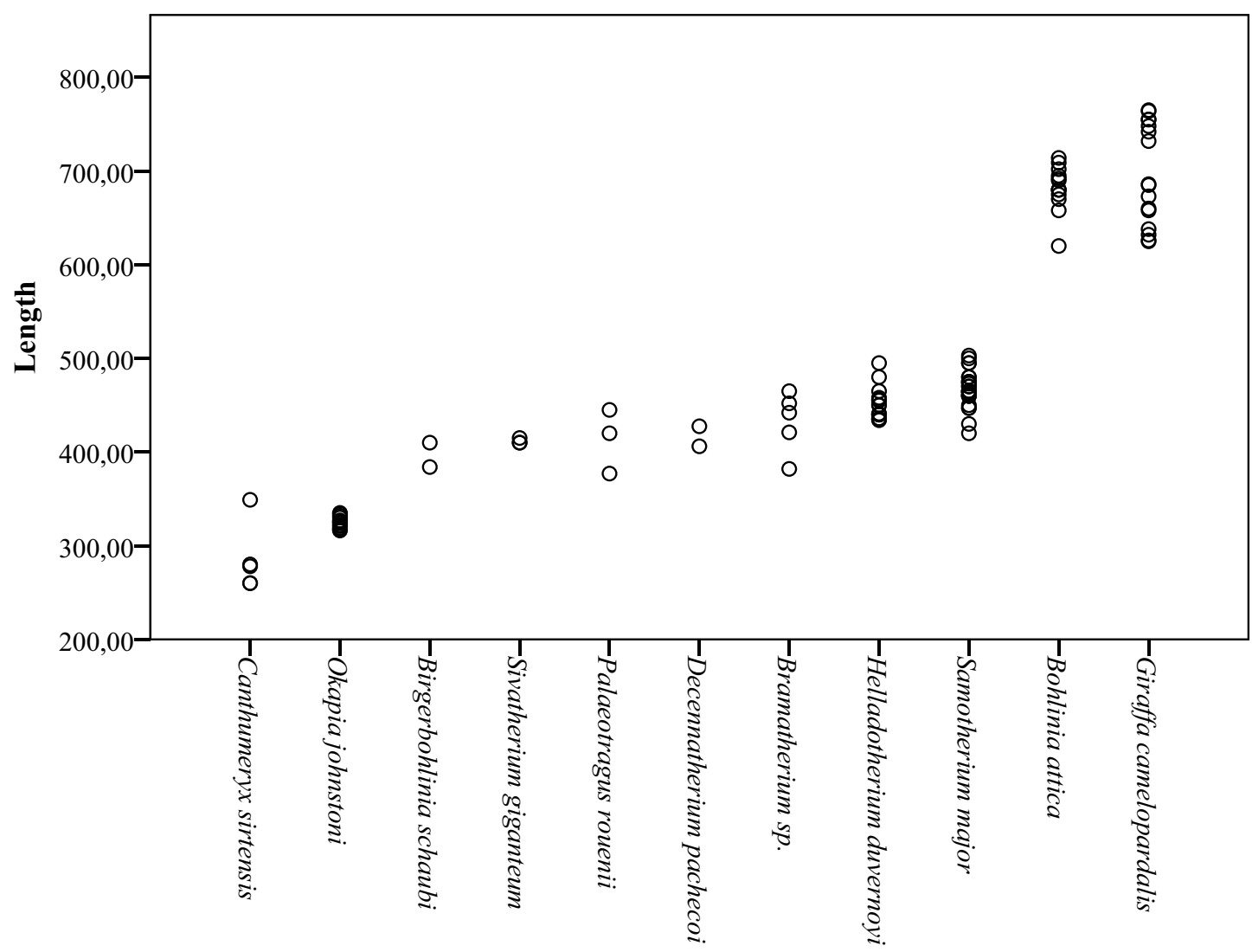

FIGURE 23. Dispersion plot with the absolute metatarsal length of the Giraffidae analyzed.

describe and separate between the different giraffid species (Hamilton, 1978; Morales and Soria, 1981; Solounias, 2007).

The oldest giraffid in our sample, Canthumeryx sirtensis, would fall in the category of short and very slender (Figure 22; Tables 1-6). Most late Miocene giraffids have medium metapodials in both length and robustness, except Palaeotragus rouenii that is on the slender side and Bohlinia attica, that has long and very slender metapodials (Figures 19, 22; Tables 1-6). The geographically younger Sivatherium giganteum falls into its own robustness category as the only extremely robust giraffid (Figures 19, 22; Tables 2, 5). The extant Okapia johnstoni is short and slender and Giraffa camelopardalis shares the same long and very slender metapodials as Bohlinia attica.

Metapodial robustness (RI) is a useful feature, giving us information about how the animal is built in terms of its gracility (Morales and Soria, 1981). All the giraffids in our analysis, with the exception of Palaeotragus rouenii, had a higher RI in the metacarpals when compared to the metatarsals (Tables 2, 5). This supports that giraffids distribute more body weight on the forelimb instead of the hindlimb, contrary to the typical condition seen in artiodactyls (Alcalde, 2012). The highest metacarpal RI of our analysis, Sivatherium giganteum, could be correlated with the presence of massive ossicones (Falconer and Cautley, 1836; Basu et al., 2016), which would place a higher weight on the anterior part of the body. The same occurs with the robust Bramatherium megacephalum (Lewis, 1939), which also bears huge ossicones and Birgerbohlinia schaubi which bears $50 \mathrm{~cm}$ long posterior ossicones (Montoya and Morales, 1991).

In addition to the robustness, we find the minimum diameter versus length provides valuable information on the limb proportions and possibly level of sexual dimorphism and variability of the different taxa. The metapodial proportions are highly consistent in Okapia johnstoni; in this taxon, the individual specimens all plot within a tight length and width range (Figures 21, 24). The metapodials of Sivatherium giganteum and Helladotherium duvernoyi, however, are more variable in minimum diameter, and those of the modern giraffe are variable in both length and width. The variability in 


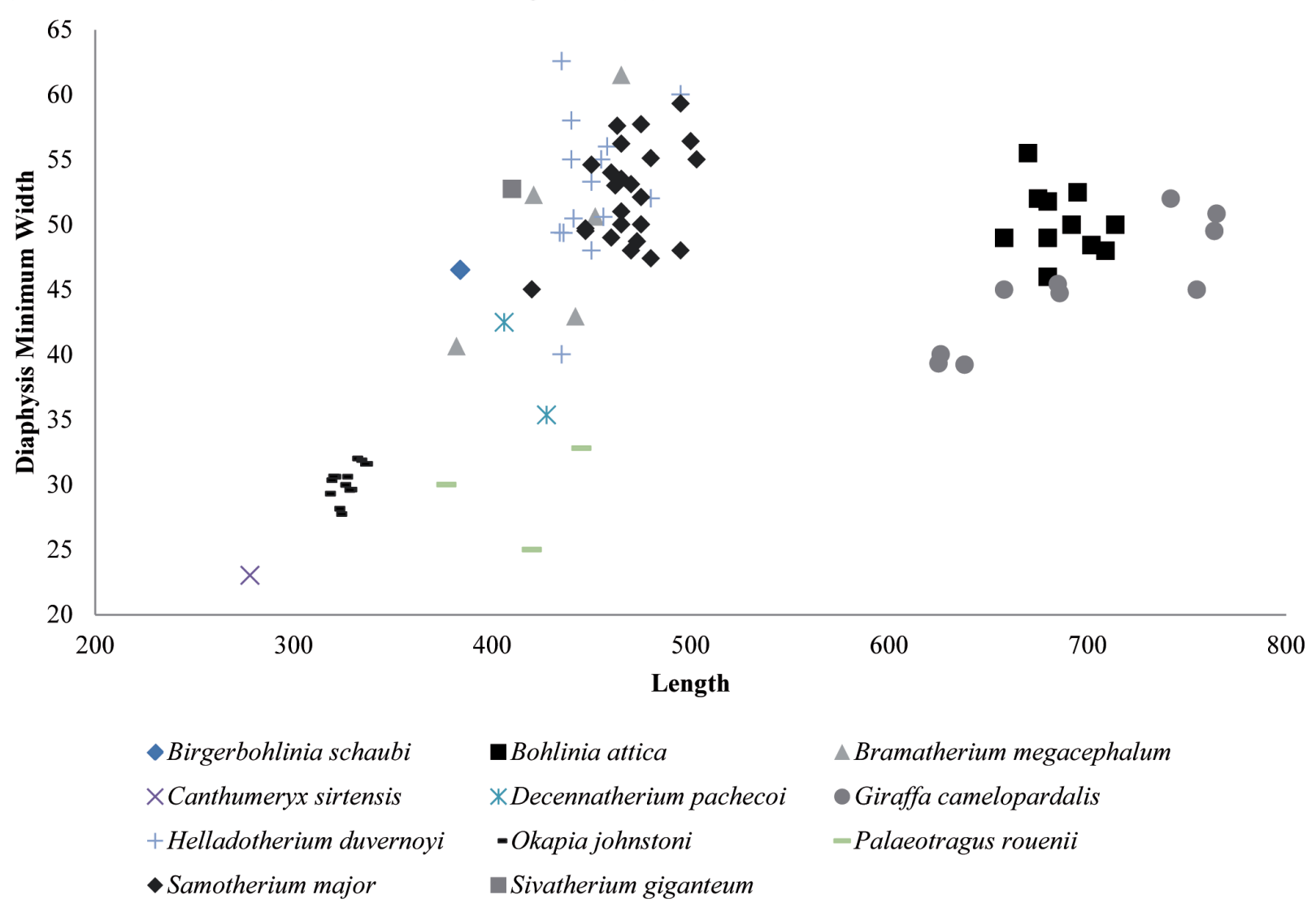

FIGURE 24. Dispersion plot showing the total length of the metatarsals versus the midshaft minimum transverse diameter of the Giraffidae analyzed.

Giraffa camelopardalis limb proportions may represent the existence multiple species or subspecies, consistent with genetic studies (Brown et al., 2007; Fennessy et al., 2016). This variability may also represent a higher degree of sexual dimorphism, where the wide range includes the smaller sized females mixed with the larger males in our dataset.

Giraffa camelopardalis exhibits extreme cervical elongation that exceeds that of most living and extinct ruminants, therefore providing substantial weight on the anterior portion of the body (Danowitz and Solounias, 2015). The G. camelopardalis metapodials, however, are slender, and studies show that the humerus is the only appendicular bone that becomes more robust with regard to body mass and bone length (van Sittert et al., 2015), suggesting a different functional adaptation to increasingly high loads in the giraffe. In fact, the decreased vertical angle of the giraffe metacarpus seems to act as a possible adaptation to the biomechanical demands imposed upon it by its slender shape (van Schalkwyk, 2006).
There currently exist several cladistic analyses on Giraffidae, which are based on cranial and post cranial morphologies (Hamilton, 1978; Geraads, 1986; Solounias, 2007). Using these previously established relationships, our metapodial morphologies in question do not clearly fit on the evolutionary framework. For example, the depth of the central trough, which is a feature that clearly separates the giraffids, does not correlate with the relationships between the described taxa. We find that the combination of limb morphologies is variable among species, and that closely related taxa do not share many limb features with one another. Recent research on the cervical anatomy and evolution of Giraffidae demonstrated that neck elongation and secondary shortening clearly fits on the backdrop of an evolutionary scheme; the primitive giraffids exhibit generally elongated vertebrae, the sivatheres possess features representing neck shortening, the palaeotragines display vertebrae with cranial elongation, and the two species of Giraffa exhibit vertebrae that are elongated cranially and caudally (Danowitz et al., 2015b). In addi- 
tion, morphological studies on the neck of Samotherium show that the cervical features are intermediate between those of the giraffe and the okapi, which reflects its phylogenic position between the two extant taxa (Danowitz et al., 2015a). Skull features classically demonstrate phylogenetic patterns, as do neck morphologies; metapodials are apparently more complex and do not clearly fit the established relationships. The observed complexity of the metapodial anatomy may suggest that closely related species have specialized in locomotory factors independently of their origin within Giraffidae.

As there is no evidence for dwarfism in giraffids so far, length categories can be useful to identify and compare genera. In addition, the absolute length of the metapodials provides information about the neck elongation state, especially in the cases were the elongation is very high like in Bohlinia attica and Giraffa camelopardalis, as it would not be possible for a short-necked animal to drink with such long limbs when they reach their adult size (Solounias, 2007; Danowitz et al., 2015b). We find that plotting the length versus proximal transverse diameter gives an idea of relative slenderness of the limbs, and provides better separation between individual giraffids. Sivatherium giganteum exhibits the stockiest limbs, and Bohlinia attica and Giraffa camelopardalis possess long and slender metapodials (Figures 20, 23). Interestingly, the dimensions of Samotherium major match closely to those seen in the majority of the sivatheres, including Helladotherium duvernoyi, Bramatherium megacephalum, and Birgerbohlinia schaubi. The absolute length, slenderness, RI, and morphological features together allow for better separation of giraffid genera and can facilitate future phylogenetic analyses.

\section{CONCLUSIONS}

While many anatomical characteristics are shared between several taxa, each giraffid exhibits a unique combination of morphological metapodial features, which can be used to diagnose and separate genera. Using our detailed morphological limb descriptions, and our simplified character tables (Figures 4, 7, 16, 17), metapodial specimens can be easily identified. Our key anatomical features described can be used to differentiate and classify the various genera of Giraffidae. We find the proximo-palmar/plantar metapodial surface to be the most diagnostic region of the metapodial, and descriptions allow for effective genus comparisons. The depth of the central trough is a useful feature that clearly differentiates between the various taxa, as is the presence and orientation of the newly described pygmaios. Further, using the robustness index and other dimensional values allows for evaluation of body size, weight distribution, and further taxon separations. The robustness of the metapodial may reflect the presence of heavy ossicones on the skull. We find that the limb patterns do not clearly fit the previously established phylogenetic relationships, suggesting that metapodial evolution is more complex than that of the neck and skull.

\section{ACKNOWLEDGMENTS}

MR acknowledges a FPI 2012 predoctoral grant (Spanish Government MINECO), as well as a FPI 2014 and 2015 short stay grants (Spanish Government MINECO). We thank P. Brewer, S. Pappa and NHM, J. Galkin, E. Hoeger, and E. Westwig and AMNH, P. Pérez and MNCN, C. Argot and $\mathrm{MNHN}, \mathrm{M}$. Leakey and KNM, M.Weidmann and R.Merchant and MGL, P. Montoya and MGUV, U. Menkweld and NHMBe, and L. Celià, D. De Miguel and ICP for access to collections and assistance. We also acknowledge the referees and editors of the Paleontologia Electronica journal for their comments that improved the quality of the original manuscript. NS used personal funds for this study.

\section{REFERENCES}

Alcalde, G.M. 2012. Caracterización ecomorfológica del del esqueleto postcraneal en rumiantes (Artiodactyla, Mammalia). Aplicación en la inferencia de las adaptaciones ecológicas de los rumiantes del PlioPleistoceno de España. Tesis Doctoral. Universidad Complutense de Madrid, Madrid, Spain.

Alexjew, A. 1916. Animaux Fossiles du Village NovoElisavetovka, Odessa.

Bartosiewicz, L., van Neer, W., and Lentacker, A. 1993. Metapodial asymmetry in draft cattle. International Journal of Osteoarchaeology, 3:69-75.

Basu, C., Falkingham, P.L., and Hutchinson, J.R. 2016. The extinct, giant giraffid Sivatherium giganteum: skeletal reconstruction and body mass estimation. Biology Letters, 12:20150940.

Bohlin, B. 1926. Die Familie Giraffidae. Palaeontologia Sinica, Peking C 4 1:1-170.

Borissiak, A. 1914. Mammifères fosiles de Sébastpol: I. Trudy geologischeskogo Komiteta, 137:1-154.

Bover, P., Quintana, J., and Alcover, J.A. 2010. A new species of Myotragus Bate, 1909 (Artiodactyla, Caprinae) from the Early Pliocene of Mallorca (Balearic Islands, western Mediterranean). Geological Magazine, 147:871-885.

Breyer, J.A. 1983. The biostratigraphic utility of camel metapodials. Journal of Paleontology, 57:302-307. 
Brisson, M.J. 1756. Regnum Animale in Classes IX Distributum, Sive Synopsis Methodica. Haak, Leiden.

Brown, D., Brenneman, R.A., Koepfli, K., Pollinger, J.P, Mila, B., Georgiadis, N., Louis Jr, E.E., Grether, G.F., Jacobs, D.K., and Wayne R.K. 2007. Extensive population genetic structure in the giraffe. BMC Biology, 5:57.

Churcher, C. 1970. Two new upper Miocene giraffids from Fort Ternan, Kenya, East Africa: Palaeotragus primaevus $\mathrm{n}$. sp. and Samotherium africanum n. sp., p. 1-106. In Leakey, L.S.B and Savage, R.J.G. (eds.), Fossil Vertebrates of Africa, Volume 2. Academic Press, London and New York.

Colbert, E.H. 1935. Siwalik Mammals in the American Museum of Natural History. Transactions of the American Philosophical Society, 26:323-375.

Crusafont, M. 1952. Los jiráfidos fósiles de España. Tesis Doctoral. Diputación Provincial de Barcelona. Memorias y comunicaciones del Instituto Geológico VIII: Premio extraordinario de Doctorado, Barcelona, Spain.

Dagg, A.I. and Foster, J.B. 1976. The Giraffe: its Biology, Behaviour, and Ecology. Van Nostrand Reinhold Company, New York.

Danowitz, M., Domalski, R., and Solounias, N. 2015a. The cervical anatomy of Samotherium, an intermediate-necked giraffid. Royal Society Open Science, 2:150521.

Danowitz, M., Hou, S., Mihlbachler, M., Hastings, V., and Solounias, N. 2016. A combined-mesowear analysis of late Miocene giraffids from North Chinese and Greek localities of the Pikermian Biome. Palaeogeography, Palaeoclimatology, Palaeoecology, 449:194-204.

Danowitz, M. and Solounias, N. 2015. The cervical osteology of Okapia johnstoni and Giraffa camelopardalis. PLoS ONE, 10:e0136552.

Danowitz, M., Vasilyev, A., Kortlandt, V., and Solounias, N. 2015b. Fossil evidence and stages of elongation of the Giraffa camelopardalis neck. Royal Society Open Science, 2:150393.

Dietrich, W.O. 1942. Ältestquartäre säugetiere aus der südlichen Serengeti, Deutsch-Ostafrika. Palaeontographica, 94:43-192.

Falconer, H. 1845. Description of Some Fossil Remains of Dinotherium, Giraffe, and other Mammalia, from the Gulf of Cambay, Western Coast of India, Chiefly from the Collection Presented by Captain Fulljames, of the Bombay Engineers, to the Museum of the Geological Society. Quarterly Journal of the Geological Society, 1:356-372.

Falconer, H. 1868. Paleontological memoirs and notes. R. Hardwick, London.

Falconer, H. and Cautley, P.T. 1836. Sivatherium giganteum, a new fossil ruminant genus, from the valley of the Markanda, in the Sivalik branch of the Sub-Himalayan Mountains. Journal of the Asiatic Society of Bengal, 5:38-50.
Fennessy, J., Bidon, T., Reuss, F., Kumar, V., Elkan, P., Nilsson, M. A., Vamberger, M. Fritz, $U$ and Janke, A. (2016). Multi-locus Analyses Reveal Four Giraffe Species Instead of One. Current Biology, 26(18), 2543-2549.

Fritz, U., and Janke, A. 2016. Multi-locus analyses reveal four giraffe species instead of one. Current Biology, 26:1-7.

Forsyth Major, C.I. 1888. Sur un gisement d'ossements fossiles dans l'île de Samos contemporains de l'âge de Pikermi. Comptes rendus hebdomadaires des séances de l'Académie des sciences, 117:11781181.

Fragomeni, A. and Prothero, D.R. 2011. Stasis in late Quaternary birds from the La Brea tar pits during the last glacial-interglacial cycle. New Mexico Museum of Natural History Bulletin, 53:511-516.

Gaudry, A. 1861. Animaux Fossiles de L'Attique Résultats des fouilles exécutées en Grèce sous les auspices de l'Académie des sciences. Comptes rendus hebdomadaires des séances de l'Académie des sciences, 51:802-804.

Gaudry, A., Fischer, P., and Tournouer, R. 1873. Étude sur les vertébrés par Albert Gaudry, p. 5-171. In Savy, F. (ed.), Animaux fossiles du Mont Léberon (Vaucluse). Librairie de la Société Géologique de France.

Gaudry, A. and Lartet, E. 1856. Résultats des recherches paléontologiques entreprises dans l'Attique sous les auspices de l'Académie. Comptes rendus hebdomadaires des séances de l'Académie des sciences, 43:271-274.

Geraads, D. 1979. Les Giraffinae (Artiodactyla, Mammalia) du Miocène supérieur de la région de Thessalonique (Grèce). Bulletin du Muséum national d'Histoire naturelle, 4è sér. C, 1:377-389.

Geraads, D. 1986. Remarques sur la systématique et phyloégnie des Les Giraffidae (Artiodactyla, Mammalia). Geobios, 19:465-477.

Geraads, D. 1994. Les gisements de mammifères du Miocène supérieur de Kemiklitepe, Turquie: Giraffidae. Bulletin du Muséum national d'Histoire naturelle, 4è sér. C, 16:159-172.

Geraads, D. 1998. Le gisement de vertébrés pliocènes de Çalta, Ankara, Turquie: Cervidae et Giraffidae. Geodiversitas, 20:455-465.

Geraads, D. 2009. Giraffidae (Mammalia) de la fin du Néogène de la République de Macédoine (ARYM). Geodiversitas, 31:893-908.

Geraads, D. and Güleç, E. 1999. A Bramatherium skull (Giraffidae, Mammalia) from the late Miocene of Kavakdere (Central Turkey). Biogeographic and phylogenetic implications. Bulletin of the Mineral Research and Exploration, 121:51-56.

Geraads, D., Kaya, T., and Mayda, S. 2005. Late Miocene large mammals from Yulafli, Thrace region, Turkey, and their biogeographic implications. Acta Palaeontologica Polonica, 50:523-544. 
Gray, J.E. 1821. On the Natural Arrangement of Vertebrate Animals. London Medical Repository, 15:297310.

Hamilton, W.R. 1973. The lower Miocene ruminants of Gebel Zelten, Libya. Bulletin of the British Museum (Natural History) Geology, 21:73-150.

Hamilton, W.R. 1978. Fossil Giraffes from the Miocene of Africa and a Revision of the Phylogeny of the Giraffoidea. Philosophical Transactions of the Royal Society of London. Series B, Biological Sciences, 283:165-229.

Harris, J. 1976. Giraffidae from the East Rudolf succession. p. 264-267. In Coppens, Y., Howell, F.C., Isaac, G.L., and Leakey, R.E. (eds.), Earliest Man and Environments in the Lake Rudolf Basin. Chicago University Press, Chicago.

Heintz, E. 1963. Les characte?res distinctifs entre me?tatarses de Cervidae et Bovidae actuels et fossils. Mammalia, 27:200-209.

International Committee on Veterinary Nomenclature. 2012. Nomina anatomica veterinaria. 5th ed. The Committee: Hannover, Columbia, Gent, Sapporo.

Janis, C.M. and Scott, K.M. 1987. The interrelationships of higher ruminant families with special emphasis on the Cervoidea. American Museum Novitates, 2893:185.

Janis, C.M. and Theodor, J.M. 2014. Cranial and postcranial morphological data in ruminant phylogenetics. Zitteliana, (2014):15-31.

Janis, C.M., Theodor, J.M., and Boisvert, B. 2002. Locomotor evolution in camels revisited: a quantitative analysis of pedal anatomy and the acquisition of the pacing gait. Journal of Vertebrate Paleontology, 22:110-121.

Kostopoulos, D.S. 2009. The Late Miocene Mammal Faunas of the Mytilinii Basin, Samos Island, Greece: New Collection. Giraffidae. Beiträge zur Paläontologie, 31:345-389.

Kostopoulos, D.S., Koliadimou, K.K., and Koufos, G.D. 1996. The giraffids (Mammalia, Artiodactyla) from the late Miocene mammalian localities of Nikiti (Macedonia, Greece). Palaeontographica Abteilung $A$, 239:61-88.

Lankester, E.R. 1901. On Okapia johnstoni. Proceedings of the Zoological Society of London,16:279-281.

Leinders, J.J.M. 1979. On the osteology and function of the digits of some ruminants and their bearing on taxonomy. Zietschrift für Säugetierkunde, 44:305-318.

Leinders, J.J.M. and Sondaar, P.Y. 1974. On functional fusions in foot bones of ungulates. Zietschrift für Säugetierkunde, 39:109-115.

Lewis, G.E. 1939. A new Bramatherium skull. American Journal of Science, 237:275-280.

Linnaeus, C. 1758. Systema Naturae per Regna tria Naturae, secundum Classes, Ordines, Genera, Species, cum Characteribus, Differentiis, Synonymis, Locis. Tenth edition. Laurentii Salvii, Stockholm, Sweden.
Lydekker, R. 1876. Indian Tertiary and Post-Tertiary Vertebrata. Descriptions of the molar teeth and other remains of Mammalia. Memoirs of the Geological Survey of India, 1:19-83.

Matthew, W.D. 1929. Critical Observations Upon Siwalik Mammals, Bulletin of the American Museum of Natural History, 56:437-560.

McMahon, T.A. 1975. Allometry and biomechanics: limb bones in adult ungulates. The American Naturalist, 109:547-563.

Mecquenem, R. 1924. Contribution á l'étude des fossiles de Maragha. Annales de Paléontologie, 13-14:135160.

Melentis, I.K. 1974. Helladotherium duvernoyi Gaudry, 1860 aus Pikermi (Griechenland). Scientific Epetiris: Faculty of Natural and Mathematical Sciences, 14:65-73.

Montgelard, C., Catzeflis, F.M., and Douzery, E. 1997. Phylogenetic relationships of artiodactyls and cetaceans as deduced from the comparison of cytochrome $b$ and $12 S$ rRNA mitochondrial sequences. Molecular Biology and Evolution, 14:550-559.

Montoya, P. and Morales, J. 1991. Birgerbohlinia schaubi Crusafont, 1952 (Giraffidae, Mammalia) del Turoliense inferior de Crevillente-2 (Alicante, España). Filogenia e historia biogeográfica de la subfamilia Sivatheriinae. Bulletin du Muséum national d'Histoire naturelle, Paris, $4^{\circ}$ sér., 13:177-200.

Morales, J. and Soria, D. 1981. Los artiodáctilos de Los Valles de Fuentidueña (Segovia). Estudios geológicos, 37:477-501.

Quiralte, M.V. 2011. Historia evolutiva de los rumiantes (Mammalia, Artiodactyla) del Mioceno inferior de las cuencas centrales ibéricas. Tesis Doctoral. Universidad Autónoma de Madrid, Madrid, Spain.

Schlosser, M. 1921. Die Hipparionfauna von Veles Mazedonien. Abhldungen bayerische Academie Wissenschaften München, 29:1-54.

Sclater, P.L. 1901. On an apparently new species of Zebra from the Semliki forest. Proccedings of the Zoological Society of London, 1:50-52.

Scopoli, G.A. 1777. Introductio ad historiam naturalem, sistens genera lapidium, planatarum, et animalium hactenus detecta, caracteribus essentialibus donata, in tribus divisa, subinde ad leges naturae. Gerle, Prague.

Scott, K.M. 1985. Allometric trends and locomotor adaptations in the Bovine. Bulletin of the American Museum of Natural History, 179:197-288.

Silvia, W.J., Hamilton, C.H., and Silvia, W.F. 2014.The occurrence of metatarsal splint bones in ruminants and their potential use in establishing phylogenetic relationships. Zitteliana, (2014):155-162.

Singer, R. and Boné, E. 1960. Modern giraffes and the fossil giraffids of Africa. Annals of the South Africa Museum, 45:375-548.

Solounias, N. 2007. Family Giraffidae, p. 257-277. In Prothero, D.R.F. and Foss, S.E. (eds.), The Evolution 
of Artiodactyls. The Johns Hopkins University Press, Baltimore.

Thewissen, J.G. and Madar, S.I. 1999. Ankle morphology of the earliest cetaceans and its implications for the phylogenetic relations among ungulates. Systematic Biology, 48:21-30.

van der Geer, A.E. 2005. Island ruminants and parallel evolution of functional structures. Quaternaire, 2:231240.

van Schalkwyk, O.L. 2006. Bone density and Calcium and Phosphorus content of the giraffe (Giraffa camel- opardalis) and African buffalo (Syncerus caffer) skeletons. Journal of Zoology, 264:307-315.

van Sittert, S., Skinner, J., and Mitchell, G. 2015. Scaling of the appendicular skeleton of the giraffe (Giraffa camelopardalis). Journal of morphology, 276:503516.

Woodman, N. and Gaffney S.A. 2014. Can they dig it? Functional morphology and semifossoriality among small?eared shrews, genus Cryptotis (Mammalia, Soricidae). Journal of Morphology, 275:745-759. 